
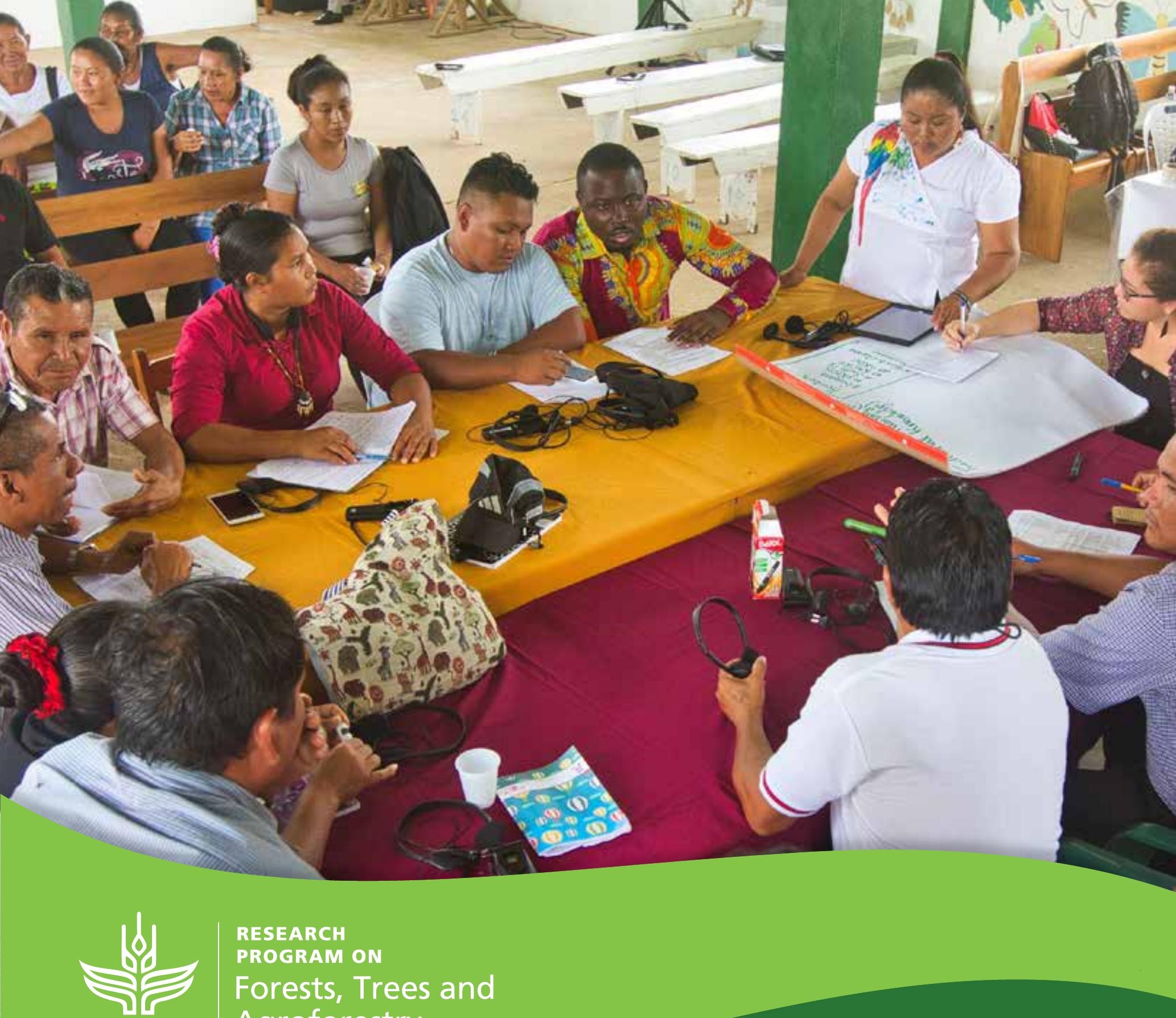

RESEARCH
PROGRAM ON

Forests, Trees and Agroforestry

CGIAR

Capacity Needs Assessment of

CIFOR, ICRAF and their partners for the implementation of the CGIAR Research Program on Forestry, Trees and Agroforestry (FTA)

Phase II, 2017-2021 



\section{Capacity Needs Assessment of CIFOR, ICRAF and their partners for the implementation of the CGIAR Research Program on Forestry, Trees and Agroforestry (FTA)}

Phase II, 2017-2021 
(c) 2020 The CGIAR Research Program on Forests, Trees and Agroforestry (FTA)

(c) (i) Content in this publication is licensed under a Creative Commons Attribution 4.0 International (CC BY 4.0), http://creativecommons.org/licenses/by/4.0/

DOI: $10.17528 /$ cifor/007706

Bourne M, Chesterman S, Wardell DA and Mehmood-UI-Hassan M. 2020. Capacity Needs Assessment of CIFOR, ICRAF and their partners for the implementation of the CGIAR Research Program on Forestry, Trees and Agroforestry (FTA): Phase II, 2017-2021. Bogor, Indonesia: The CGIAR Research Program on Forests, Trees and Agroforestry (FTA).

Cover photos by Neil Palmer/CIAT (front) and Axel Fassio/CIFOR (back).

CGIAR Research Program on Forests, Trees and Agroforestry CIFOR Headquarters Jalan CIFOR

Situ Gede, Sindang Barang

Bogor Barat 16115

Indonesia

T +62-251-8622-622

E cgiarforestsandtrees@cgiar.org

foreststreesagroforestry.org

We would like to thank all funding partners who supported this research through their contributions to the CGIAR Fund. For a full list of the 'CGIAR Fund' funding partners please see: http://www.cgiar.org/our-funders/

Any views expressed in this publication are those of the authors. They do not necessarily represent the views of The CGIAR Research Program on Forests, Trees and Agroforestry (FTA), the editors, the authors' institutions, the financial sponsors or the reviewers. 


\section{Contents}

$\begin{array}{ll}\text { Acronyms } & \text { v }\end{array}$

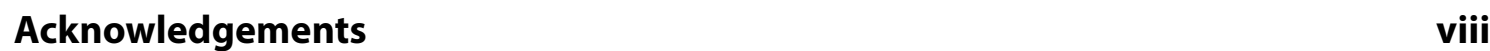

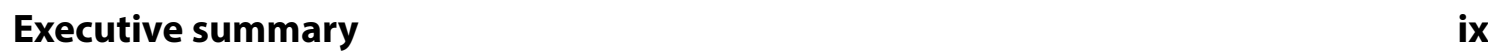

1 Introduction 1

1.1 Capacity development in CGIAR 1

1.2 Flagship Programs and theories of change 4

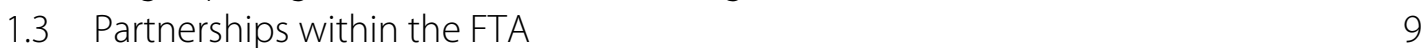

2 Methodology 11

3 Results 13

3.1 Structure of findings 13

3.2 Expertise capacity 13

3.3 Partnering and networking capacities 14

3.4 Capacity to mobilize financial resources 31

3.5 Managerial capacities $\quad 32$

4 Monitoring and reporting $\quad 35$

5 Recommendations across FTA II to enhance capacity to deliver on research outcomes and achieve greater impacts

$\begin{array}{lr}\text { Bibliography } & 38\end{array}$

$\begin{array}{lr}\text { Appendices } & \mathbf{4 0}\end{array}$

1 List of FTA operational priorities $\quad 40$

2 Interviewees 42

$3 \quad$ Interview guiding questions 44 


\section{List of figures, tables and boxes}

\section{Tables}

1 Summarized overview of how CapDev was addressed and how CGIAR CapDev elements (Box 1) are recognized in the FTA Phase II flagship proposals

2 Analytical framework for capacity assessment

3 Examples of important partners for FPs 1, 2, 3, 4 and 5, as outlined in the FTA Phase II proposal

4 Core areas and linked recommendations to address capacity gaps

5 Matrix of capacity enhancement recommendations for select progress markers in three selected flagships

\section{Figures}

1 Sociogram showing FTA's managing partners and the countries in which they conduct activities

\section{Boxes}

1 Key elements of capacity development

2 Private sector engagement: the case of Mars Inc.

3 Evidence-informed decision making at the subnational level - The SHARED methodology in Turkana County, Kenya

4 Improving governance by building capacity in the Democratic Republic of he Congo

5 CIFOR collaboration with final-year law students at national universities in Tanzania, Zambia and Mozambique and the International Development Law Organization

6 Strengthening research capacities through partial fellowship programs -

DAAD-ICRAF In-country/In-region PhD Fellowship Program

8 African Plant Breeding Academy of the African Orphan Crops Consortium (AOCC)

9 Building capacity for facilitation and soft skills enhancement - SHARED Decision Hub Facilitator Training 


\section{Acronyms}

AfPBA

APFORGEN

ASB

ASTI

BECA

CacaoNet

CATIE

CBD

CCAFS

CDI

CGIAR

CIFOR

CIRAD

COA

CODELT

COGENT

COP

CRP

EDO

EMBRAPA

ESP

FAO

FAST

FP

FSC

FTA

GASCA

GCF

GFW

ICCO

ICRAF
African Plant Breeding Academy

Asia Pacific Forest Genetic Resources Programme

Alternatives to Slash-and-Burn program

Agricultural Science and Technology Indicators

Biosciences in Eastern and Central Africa

Global Network for Cacao Genetic Resources

Tropical Agricultural Research and Higher Education Center (Centro Agronómico Tropical de Investigación y Enseñanza)

Convention on Biological Diversity

CGIAR Research Program on Climate Change, Agriculture and Food Security

Centre for Development Innovation, Wageningen University

Consultative Group on International Agriculture Research

Center for International Forestry Research

French Agricultural Research Centre for International Development

Cluster of Activities

Conseil pour la Défense Environnementale par la Légalité et la Traçabilité

Coconut Genetic Resources for Enhanced Livelihoods

Conference of the Parties

CGIAR Research Program

End-of-Program Outcome

Empresa Brasileira de Pesquisa Agropecuária Ministério da Agricultura, Pecuária e Abastecimento

Ecosystem Services Partnership

The Food and Agriculture Organization of the United Nations

Finance Alliance for Sustainable Trade

Flagship Program (or'flagship')

Forest Stewardship Council

CGIAR Research Program on Forests, Trees and Agroforestry

Global Alliance for Smart Cities in Africa

Global Climate Fund

Global Forest Watch

International Cocoa Organization

World Agroforestry Centre 


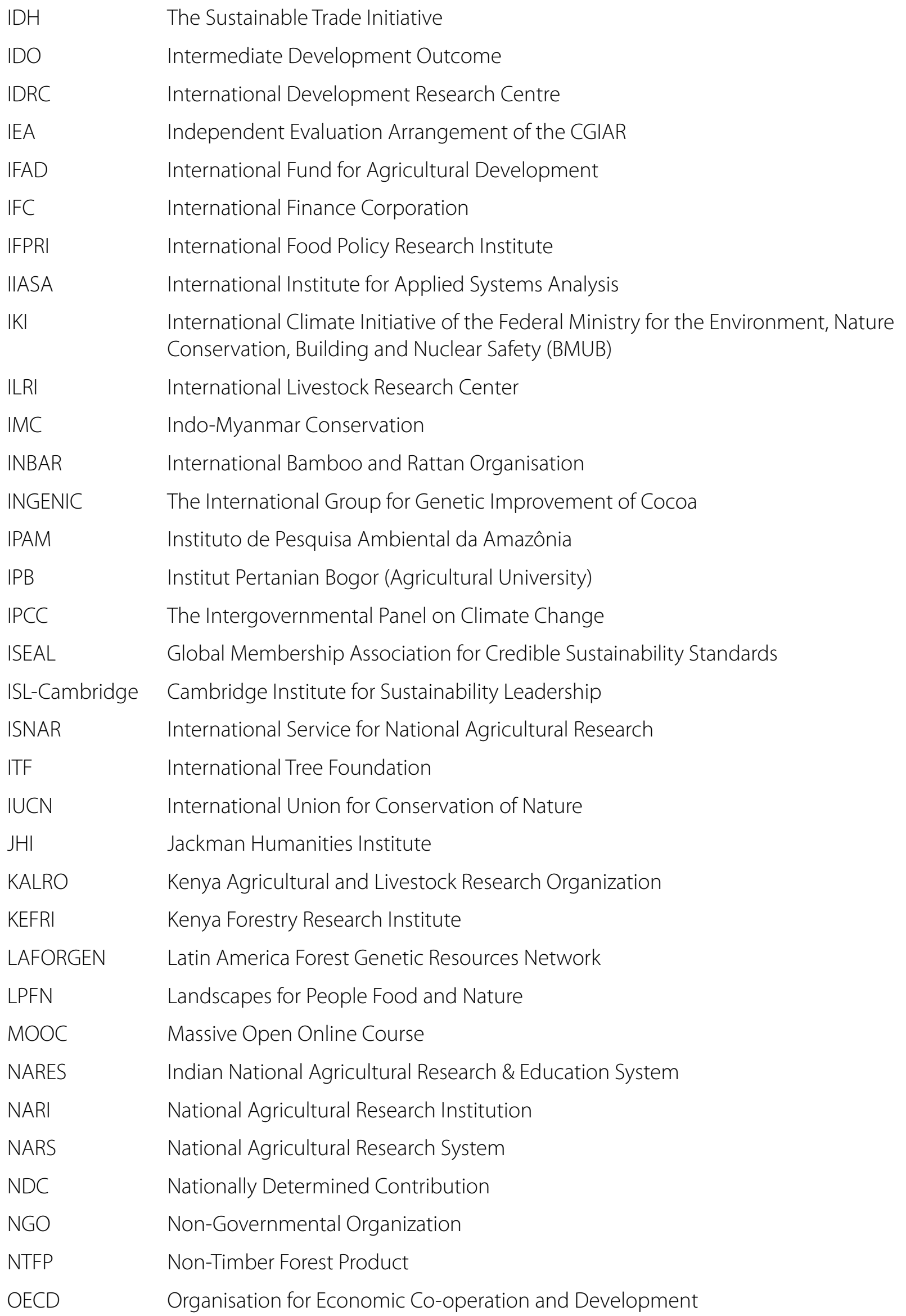


PIM

RFF

RinD

RMT

RRC

RRI

RSPO

RUFORUM

SAN

SBSTA

SDG

SEI

SHARED

SLO

$S M B$

SME

SMO

SNV

SPDA

SRF

TBI

TFA 2020

TGR

TNC

TOC

UC Davis

UNDP

UNEP-FI

UNFCCC

UPM

WB

WLE

WRI

WWF
CGIAR Research Program on Policies, Institutions, and Markets

Resources For the Future

Research in Development

Resource Mobilization Team

Rural Resource Center

Rights and Resources Initiative

Roundtable on Sustainable Palm Oil

Regional Universities Forum for Capacity Building in Agriculture

Sustainable Agriculture Network

Subsidiary Body for Scientific and Technological Advice

Sustainable Development Goal

Stockholm Environment Institute

STAKEHOLDER Hub for Evidence Informed and Risk Informed Decision Making

System Level Outcomes

System Management Board

Small and Medium Enterprise

System Management Office

SNV Netherlands Development Organisation

Sociedad Peruana de Derecho Ambiental

Strategy and Results Framework

Tropenbos International

Tropical Forest Alliance

Tree Genetic Resources

The Nature Conservancy

Theory of Change

University of California, Davis

United Nations Development Programme

United Nations Environment Programme Finance Initiative

United Nations Framework Convention on Climate Change

Universiti Putra Malaysia

The World Bank

CGIAR Research Program on Water, Land and Ecosystems

World Institute Resource

World Wide Fund for Nature 


\section{Acknowledgements}

In memory of Muhammad Mehmood-Ul-Hassan who died on 20 March 2020 before the finalization of this publication.

Mehmood joined ICRAF in October 2012. He was the founder and driving force behind ICRAF's Capacity Development Unit (CDU). Mehmood was widely respected due to his gentle, but resolute character. His professional and supportive attitude with all collaborators and students made him both very effective and popular. He will be deeply missed.

The authors would like to acknowledge all the individuals who generously agreed to be interviewed for this study as well as Dr. Vincent Gitz, Director of the Forestry, Trees and Agroforestry (FTA II) CGIAR Research Program for his support. 


\section{Executive summary}

The CGIAR Research Program on Forests, Trees and Agroforestry (FTA), led by the Center for International Forestry Research (CIFOR), focuses on the sustainable management of forests, trees and agroforestry systems. It offers a unique opportunity to contribute to the CGIAR Strategy and Results Framework (SRF) as well as the 17 Sustainable Development Goals (SDGs). Now in its second phase (2017-2022), FTA II is organized as a number of Flagship Programs (FP) with different thematic foci, with specific theories of change (TOCs), targets, indicators and intended outcomes for each FP. Each flagship is organized as a number of Clusters of Activities (COAs). The TOCs at the flagship level within the FTA II proposal explain the impact pathways between research outputs (specific targets and deliverables by CoA) and research outcomes, which are intended to be achieved through close collaboration and engagement with partners (defined as progress markers) and which contribute to specific Intermediate Development Outcomes (IDOs) and sub-IDOs, End-of-Program Outcomes (EDOs), System Level Outcomes (SLOs) and SDGs.

This capacity needs assessment was conducted in 2018 to identify the capacity needs of World Agroforestry (ICRAF) and CIFOR to achieve the research objectives and targets specified in the FTA II proposal 2017-2022, including the amended FP2 proposal. The capacity needs assessment focused on four key areas for analysis: partnerships, networking, resource mobilization and human resource capacities. The analysis and recommendations contained within this document result from data collated from more than 70 interviews conducted with flagship and cluster leaders and key actors within the FTA II management teams and partner organizations.

A two-part method was employed to understand if cluster and flagship teams of FTA (together with their networked partners) have sufficient capacity to deliver on their respective theories of change and impact pathways. Firstly, a review of the theories of change was undertaken within each of the flagships. Secondly, semi-structured interviews were conducted based on an analytical framework focusing on four key capacity areas: expertise, partnering and networking, resource mobilization and managerial. Key findings and recommendations are presented for each of these key capacity areas, in addition to providing some cross-cutting insights and recommendations. 



\section{Introduction}

The CGIAR Research Program on Forests, Trees and Agroforestry (FTA), led by CIFOR, focuses on the sustainable management of forests, trees and agroforestry systems. Now in its second phase (20172022), FTA II offers a unique opportunity to contribute to the CGIAR Strategy and Results Framework (SRF) as well as the 17 Sustainable Development Goals (SDGs) due to the spatial extent and the range of goods and services that forests, agroforestry systems and trees produce or maintain, and the number of people supported by these systems. The FTA program's overarching goal is to improve the current suboptimal management of forests, trees and agroforestry resources, by providing research evidence, science-based technologies and policy improvements.

In order to achieve this overarching goal, FTA II is organized as a number of Flagship Programs (FPs) with different thematic foci, and specific theories of change, targets, indicators and intended outcomes for each FP (or'flagship'). Each flagship is organized as a number of Clusters of Activities (CoAs). The five FTA II flagships are:

Flagship 1: Tree genetic resources to bridge production gaps and promote resilience

Flagship 2: Enhancing how trees and forests contribute to smallholder livelihoods

Flagship 3: Sustainable global value chains and investments for supporting forest conservation and equitable development

Flagship 4: Landscape dynamics, productivity and resilience

Flagship 5: Climate change mitigation and adaptation opportunities in forests, trees and agroforestry

This capacity needs assessment was conducted in 2018 to identify capacity needs of World Agroforestry (ICRAF) and CIFOR to achieve the research objectives and targets specified in the FTA II proposal 20172022, including the amended FP2 proposal. The capacity needs assessment focused on four key areas for analysis: partnerships, networking, resource mobilization and human resource capacities. The analysis and recommendations contained within this working paper reflect data collated from more than 70 interviews conducted with flagship and cluster leaders and key actors within the FTA II management teams and partner organizations. The capacity needs assessment formed part of the analysis to highlight capacity gaps as input into the development of a new FTA II Capacity Development (hereinafter 'CapDev') Strategy.

\subsection{Capacity development in CGIAR}

Many low- and middle-income countries continue to be confronted with a complex of serious economic, social and environmental challenges and widespread capacity constraints. Organizational capacities remain one of the most common bottlenecks in the development process. Capacity development may include formal (basic and higher) education and distance learning, internships, advisory and extension services, partnerships, knowledge networks and leadership development for individuals and organizations to effect change and to strengthen capabilities for innovation, discovery and delivery. Capacity development through Official Development Assistance-financed projects has been, at best, partially successful (OECD-DAC 2000), because conceptual frameworks and indicator sets for capacity development are still largely inspired by a technocentric results-based approach, rather 
than a complex adaptive system approach. Complex adaptive system approaches put greater emphasis on changes in the behavior of, and relationships among, the participants of the process rather than on pre-specified outcomes; these approaches also facilitate more reflection about the assumptions underpinning capacity development activities and the conditions needed for behavioral change to occur and be sustained overtime (Vallejo and When 2016). Capacity development enables research and development organizations, individuals, and their networks to achieve impact. While capacity itself is internal to individuals and organizations, external actors can support its further progress through appropriate interventions. However, as these interventions form only a small part of change processes, these require constant adaptation to internal and external contextual changes (Callo-Concho et al. 2017).

The following is extracted from the Independent Evaluation Arrangement (IEA)'s CapDev evaluation completed in 2017:

Organizational capacity refers to the internal policies, arrangements, procedures, frameworks and culture that characterize a high-performing organization delivering according to its mandate, and which enable individual capacities to thrive and goals to be achieved. Capacity related to the enabling institutional environment is the collective ability of a network of entities, together with supporting rules and policies, to bring existing or new products, processes, and forms of organization into social and economic use. The CGIAR Capacity Development Framework defines institutional capacity as "the formal and informal rules that structure and constrain human behavior and interaction" (CGIAR-IEA 2017a: 2).

Institutional capacities comprise policies, arrangements, procedures, frameworks and networks that allow organizations and individuals to operate and deliver on their objectives. CGIAR's historical focus was on organizational CapDev of National Agricultural Research Institutions (NARIs), often termed 'technical assistance', particularly through the International Service for National Agricultural Research (ISNAR, 1980-2004) and subsequently an inventory of capacity through the Agricultural Science and Technology Indicators (ASTI). Fostering institutional change has been lacking in NARIs under low resource conditions, and the tendency has been to focus on structural changes.

CapDev is currently seen as a long-term progressive process rather than a one-off intervention. There is a need for pluralistic and harmonized approaches, blending different CapDev elements at different levels. For CGIAR, this leads to coordination and partnership challenges across CGIAR Research Programs (CRPs) and centers, and among external actors providing CapDev support. There is a shift from enhancing individual capacity to helping individuals and entities develop capacity, and this means that CGIAR, among other suppliers of CapDev, must ensure the relevance of contributions. This requires attention to both capacity needs assessment and assuring that the subject, level and modality best fit the needs.

CapDev is understood to encompass many activities in CGIAR. Some experts feel that CapDev has become so all-encompassing a term as to be of little use from an analytical point of view. The challenge for CGIAR is to understand that CapDev is not uniform across CGIAR. Literature on CapDev contains a number of definitions, terminology interpretations, approaches and practices, including variance between those who fund CapDev and those whose CapDev activities are funded. The International Development Research Centre (IDRC) finds that "several recent reports have shown [that] terminology for capacity development is often vague and inconsistent, and related concepts are cloudy and ill-defined" (Taylor and Ortiz 2008, 1). Additionally, there is no specific language to refer to the many different types of CapDev clearly and unambiguously. Several CapDev evaluations call for developing a CapDev 'taxonomy' to allow effective planning, implementation and reporting. However, given that CapDev is often inherent to activities that have different objectives, complete unambiguity in classification and, for example, monitoring, may not be possible (CGIAR-IEA 2017a). 
ICRAF developed a specific strategy for capacity development for the period 2013-2018 (ICRAF 2013a) at the same time as a broader ICRAF Strategy 2013-2022 Transforming Lives and Landscapes with Trees. The latter specified "developing and mobilizing capacity at institutional and individual levels" as one of six key roles in research and development. This included "identifying and filling capacity gaps for institutional, national and scientist benefit" and "assisting in raising awareness of, and mobilizing efforts of existing under-utilized capacities" (ICRAF 2013b: 15).

The (former) CGIAR Capacity Development Community of Practice (CapDev COP), in collaboration with Project Services International Inc., initiated a process in 2015 which culminated in proposing 14 indicators for the second phase of CGIAR Research Programs (Draft CGIAR Capacity Development Indicators, June 2016). After the dissolution of the CapDev COP, little, if any, further progress has been made in using the proposed set of CapDev indicators.

CIFOR has included CapDev as part of its mandate since the organization was launched (CIFOR 1995, 8), and in 2009 this emphasis was highlighted by the (then) CGIAR Science Council in its endorsement of CIFOR's Medium-Term Plan, as mentioned in its annual report in the letter from the Chair of the Board (CIFOR 2009). CapDev was then instated as Pillar 2 of CIFOR's three-pronged strategy following a CIFOR Board of Trustees decision in April 2015 and was included in the CIFOR Strategy 2016-2025 (CIFOR 2017b). It states:

Capacity development of our own staff, as well as our partners, stakeholders, journalists and students are central to our theory of change, and fundamental to achieving the impacts we seek and that are expected of us. Human and institutional capacity development is an integral part of our overall research effort, integrated into all research programs and projects from their inception. We engage in a great variety of capacity development activities in partnership with implementing partners, including universities, government agencies and NGOs. Our capacity building with external partners supports the development of both academic and technical capacity (CIFOR 2017b: 5).

However, no CapDev-specific strategy was developed until a draft was presented to the CIFOR PC meeting in April 2018. During preliminary CIFOR-ICRAF merger discussions held on 18 September 2019 a 10-point performance area framework was proposed but which did not include any explicit reference to CapDev.

Other CGIAR centers had established Capacity Strengthening Programs as early as 1985 (e.g. the International Food Policy Research Institute, IFPRI) and Capacity Development Units since 2013 (e.g. ICRAF). An impact evaluation of the former provided several useful lessons (see IFPRI 2014 and Kuyvenhoven 2018). Several findings were reaffirmed by the subsequent CGIAR-IEA CapDev evaluation (CGIAR-IEA 2017a).

More recent research argues that "the CGIAR - through its CGIAR Research Programs - is struggling to fulfill its international mandate of conducting strategic research that contributes to agricultural development and global food security. Ongoing reforms have resulted in a situation where the CGIAR is assessed as if it were a development organization. This leads the CGIAR to raise unrealistic expectations regarding the development impacts of the science conducted, resulting in ever growing distrust between the centers and the donor community. Moreover, its short-term funding cycle and current mode of safeguarding scientific quality are not conducive to doing strategic and potentially transformative research" (Leeuwis et al. 2017).

A select bibliography on CapDev relevant to CGIAR is presented in Section 6. 


\subsection{Flagship Programs and theories of change}

\subsubsection{Background}

Each of the FPs is built around a set of critical issues related to forestry, agroforestry and tree production systems. This takes into account factors such as productivity, links to the food system, and environmental and social sustainability. Consequently, the set of FPs forms an organizing structure for the dynamic mix of commodities, actors, topical focus and scales. FPs are solid constructs with explicit teams, outputs and outcomes, and more abstract and fluid working modalities between flagships aiming to integrate relevant results. Taking these structural aspects into account, the capacity needs assessment has reviewed the capacity and has generated recommendations specific to flagships, however overarching recommendations and analysis cover the flagships more generally. These recommendations take into consideration the goal of flagships, together, contributing to system level outcomes of FTA, and are targeted as operational amendments that can be made in this guise.

\subsubsection{Description of the flagships}

Flagship 1 (FP1) - 'Tree genetic resources' (TGR) - aims to bridge production gaps and promote resilience. FP1 works toward safeguarding existing genetic diversity; seeks new solutions for critical steps in the domestication and improvement of priority tree species; and investigates delivery pipelines for improved germplasm relevant to addressing the constraints for trees on farms to make desirable impacts in FP2 and FP3, while also supporting delivery systems for landscape restoration initiatives within FP4. The effective use of TGR to bridge production gaps, ensure profitability, and for the essential global diversification of production options provides important opportunities to improve livelihoods and sustain ecosystems, and is a crucial part of reversing current cycles of land degradation and deprivation. However, the role of TGR in the provision of tree products and services has often been undervalued. This has resulted in the cultivation of trees not matched to context, with poor yields and low-quality traits.

FP1 addresses the under-recognition of the importance of TGR for productive and sustainable landscapes; the lack of coordination and appropriate investment in relevant research; and the inadequate models, tools and support mechanisms for effective testing and upscaling. Activities focus on safeguarding genetic diversity, domestication and planting material delivery. By drawing on recent methodological advances in each of these three areas, effective coordinated approaches are mainstreamed to provide a route to greater impact.

The research in FP1 is focused around three CoAs. CoA1.1 looks at safeguarding diversity, CoA1.2 focuses on tree domestication to enhance products and services, and CoA 1.3 examines delivery systems for tree planting material.

Flagship 2 (FP2) - 'Enhancing how trees and forests contribute to smallholder livelihoods' -focuses on devising, testing, refining and scaling up context-appropriate and inclusive tree-based and small-scale forestry management and livelihood options. The rationale behind this flagship is that food security, nutrition and income for more than 100 million poor smallholders can be improved through better management of forests, trees and agroforestry resources underpinning their livelihood systems.

FP2 is focused on understanding the relationship between smallholder livelihoods and trees and forests. It aims to leverage this understanding to reduce poverty, increase food security and increase smallholder income in Africa, Asia and Latin America. It also aims to do this while enhancing environmental integrity, natural capital and climate change adaptability. The flagship asserts that currently $28 \%$ of household 
incomes for smallholders living at the margins of forests is derived from forest resources. Unfortunately, forest resources are currently under-utilized by smallholders due to policy constraints and the time lag it takes for high-value crops to grow. FP2 invests about half of its resources in place-based research, in order to overcome these challenges with technical solutions that can have a large impact at scale.

Its research activities are focused on CoAs. Livelihood systems analysis, synthesis and scaling (CoA2.1) provides connections across the other four CoAs: smallholder timber, food and fuel production and marketing; developing and sustaining smallholder tree-crop commodity production; trees supporting sustainable agro-ecological intensification; and sustaining silvopastoral systems for production, animal welfare and the environment.

Flagship 3 (FP3) - 'Sustainable global value chains and investments for supporting forest conservation and equitable development' - facilitates innovations in public policy, business models and private investments and finance to stimulate the sustainable supply of timber from natural and planted forests, enhance the sustainable production of high-value tree crops (oil palm, rubber, cocoa, coffee and coconut) and reduce the impacts of agricultural expansion (soybean and beef) on forests. It does this by supporting the uptake of more intensive and integrated agricultural production and forest management systems that comply with higher social and environmental standards, thus supporting forest conservation and improving the integration of smallholder and small- and medium-sized enterprises (SMEs).

FP3 addresses key global challenges associated with the need to reduce deforestation, forest degradation and conversion of species-rich agricultural and forest landscapes while meeting a growing global demand for food, feed and fiber. This entails improved public and private arrangements to enhance the governance of global value chains so that they can adhere to sustainability standards in order to reduce negative environmental impacts. It also involves supporting more intensive and integrated management and production systems with a greater participation of smallholders and SMEs in the value chains, while also emphasizing women, youth and marginalized groups.

Research activities in FP3 are structured around three CoAs with interconnected goals and approaches. CoA 1 examines the policy and institutional environment shaping the structure and dynamics of timber and agricultural commodity value chains (oil palm, rubber, soybean and beef) that are articulated to global markets and contribute significantly to deforestation and forest degradation. The second CoA focuses on business models in timber and tree-crop value chains (e.g. palm oil, cacao, coffee and coconut) that link corporations with smallholder farmers and SMEs. The third cluster assesses how the financial sector influences the social and environmental performance of value chains and businesses.

Flagship 4 (FP4) - 'Landscape dynamics, productivity and resilience' - focuses on improved and more inclusive landscape planning, governance and adaptive management approaches to better reconcile trade-offs. The rationale behind this flagship is that there is a need for understanding what really matters at the landscape scale, in terms of patterns of change, trade-offs between ecosystems services, production, landscape diversity and governance.

FP4 is focused on addressing the multifunctionality gap. That is, the balancing of land use for multiple functions including the production of goods and the maintenance of environmental integrity, while also considering human rights, tenure, poverty, migration and limited opportunities for young people. This results in actual landscapes tending to operate well below their potential. FP4 combines observations of changes in land use and changes in the provision of ecosystem services, and focuses on the search for alternative or better methods of land use. 
Its research activities are divided into four CoAs. Firstly, determining the current patterns and intensities of changes in tree cover through Sentinel Landscapes. Secondly, understanding the consequences of changes for the functions of the ecosystem. Thirdly, analyzing the way that landscape diversity contributes to healthy diets for smallholders and other consumers. Fourthly, the creation of contextualized generic theories of change and incentives to provide a roadmap for balanced and productive land use.

Flagship 5 (FP5) - 'Climate change mitigation and adaptation opportunities in forests, trees and agroforestry' - focuses on harnessing the importance of forests in climate change mitigation and adaptation as recognized in the Paris Climate Agreement. It endorses reducing emissions from deforestation and forest degradation (REDD+), allows for alternative (non-market) policy approaches such as joint mitigation and adaptation, and emphasizes the importance of non-carbon benefits and equity for sustainable development. Countries should develop capacities and grow national ambitions through their Nationally Determined Contributions (NDCs) towards reaching the $2.0^{\circ} \mathrm{C} / 1.5^{\circ} \mathrm{C}$ goal.

FP5 provides climate change policy makers and practitioner communities with access to information, analysis and tools needed to design and implement policies for mitigation, adaptation and bioenergy, as well as to create enabling conditions to assess the degree to which REDD+ has delivered effective, costefficient and equitable carbon and non-carbon benefits. To achieve these goals, FP5 builds on tested and trusted relationships with key R\&D/delivery government and non-government partners in a number of countries.

Research is carried out in four CoAs. The first focuses on achieving climate change mitigation with forests, trees and agroforestry; the second on adaptation of people and forests to climate change; the third on bioenergy and performance assessment of carbon; and the fourth on emissions, ecosystem services and policies. The CoAs are integrated with research in other FPs and CRPs: FP5 links with FP2 on adaptation, with FP3 on private-sector approaches to mitigation and with FP4 on landscapes. FP5 also works with the CGIAR Research Programs on Climate Change, Agriculture and Food Security (CCAFS), on Policies, Institutions, and Markets (PIM), and on Water, Land and Ecosystems (WLE).

All five flagships were developed, guided by, and aim to contribute to achieving the SDGs. In November 2017, a new priority-setting process was introduced in FTA to promote focus, alignment and coherence of all proposed activities, and as a mechanism to work across disciplines and across flagships. Further details are presented in section 3.3.

\subsubsection{Overall impact pathways and theory of change}

FTA Il's theory of change (TOC) is a living and dynamic framework that describes how FTA will:

- $\quad$ undertake high-quality FTA research in collaboration with partners and other stakeholders to

- co-generate relevant, credible and legitimate knowledge that

- informs and facilitates improved policy and practice and institutional change, which

- contributes to the delivery of positive, equitable and inclusive development and

- environmental outcomes, including those associated with CGIAR's Strategic Results Framework, and more broadly the 17 SDGs.

The FTA Il theory of change is founded on five interrelated principles:

1. Co-learning. Investing in meaningful stakeholder and partner engagement and the 'co-generation' of knowledge and evidence throughout the research cycle - as opposed to one-way, supply-driven 'research dissemination' - significantly increases the likelihood of research relevance, use and, ultimately, developmental impact. 
2. Inter-disciplinarity. Inter-disciplinary and trans-disciplinary research approaches are generally more effective in addressing complex challenges, such as those associated with forests, trees and agroforestry.

3. Inclusivity. New scientific knowledge and evidence will translate into both greater and more inclusive, equitable and sustainable development impacts. Focused efforts are undertaken to investigate and ensure that the differentiated needs and priorities of specific groups of end-users and beneficiaries (e.g. women, youth and the poor and marginalized) are addressed throughout the research cycle - and with their own knowledge systems recognized as important points of reference.

4. Focus on end-user needs. The translation of scientific knowledge and evidence into improved policy, practice and institutions is greatly accelerated and enhanced, if complemented with:

- targeted capacity development;

- the explicit comparison of existing local, public/policy and science-based knowledge systems related to specific questions;

- $\quad$ the packaging of generated knowledge into actionable recommendations, decision-support tools (where a single decision-maker is involved) and negotiation support (where multiple stakeholders are expected to have different perspectives and interests); and

- $\quad$ structured processes to enable stakeholders to meaningfully engage with scientific data and evidence.

5. Adaptive management. Monitoring and evaluating progress along well-defined knowledge-to outcome pathways and - critically - informing management decision-making based on the resulting data and learning will further significantly facilitate the translation of quality FTA science into equitable and inclusive developmental impact.

Table 1 presents an overview of how CapDev was addressed and the extent to which CGIAR CapDev elements developed by the former CGIAR CapDev COP (Box 1) were recognized in the FTA II flagship proposals.

The TOCs at the flagship level within the FTA II proposal explain the impact pathways between research outputs (specific targets and deliverables by $\mathrm{CoA}$ ) and research outcomes, which are intended to be achieved through close collaboration and engagement with partners (defined as progress markers) and which contribute to specific Intermediate Development Outcomes (IDOs) and sub-IDOs, End-of-Program Outcomes (EDOs), System Level Outcomes (SLOs) and SDGs.

Capacity development represents an essential component of the FTA Phase II TOC, but it is only given cursory attention in the FTA Phase II proposal, representing only between 1-2\% of the full text dedicated to each flagship. No flagship has developed either a partnership strategy or a specific strategy to secure the human and financial resources necessary to achieve TOC outputs and outcomes. Some flagships make no explicit reference to CapDev in their TOCs.

In general, CapDev varies across flagships in terms of the extent to which CGIAR CapDev 'elements' (CGIAR 2015) have been applied, or not. FP2 did put CapDev center stage in a revised proposal, with emphasis on community-based organizations. This, despite the IEA CapDev evaluation recommendation \#3 to de-emphasize or subcontract such types of CapDev activities.

Both FP1 and FP2 recognized the importance of future research leaders (CapDev Element 4). In practice, CGIAR scientists are often over-stretched to ensure adequate support for, and supervision of young scientists. In 2018, CIFOR and ICRAF jointly organized two specialist short courses on 'How to write a scientific article'1 to assist 15 young scientists from CIFOR, ICRAF, Bioversity International and ILRI as

1 The course material was first developed by CIFOR for doctoral candidates at the University of Kisangani, Democratic Republic of the Congo during the EC-financed Forets et Changement Climatique au Congo project. 
they embarked on their postgraduate studies. Additional discussions are needed to ensure that the performance metrics for individual scientists give adequate recognition of the importance and value of mentoring young scientists.

For FP3, only four out of six CapDev strategies presented in the flagship proposal are still relevant, as both the CGIAR CapDev COP and The Landscape Fund no longer exist (FTA 2017a). In FP3, a new IDRC and FTA-funded research project focuses on a gendered value chain (shea nuts and shea butter) in Burkina Faso, with significant linkages to CapDev through engagement with Burkinabe research (e.g. Institut de I'Environnement et Recherches Agricoles - INERA), development (e.g. Netherlands Development Organisation - SNV) and university institutions (e.g. Universite Nazi Boni) (as per CapDev element 5).

Table 1. Summarized overview of how CapDev was addressed and how CGIAR CapDev elements (Box 1) are recognized in the FTA Phase II flagship proposals

\begin{tabular}{|c|c|c|c|c|c|c|c|c|c|c|c|}
\hline \multirow{2}{*}{ Flagship } & \multicolumn{10}{|c|}{ CapDev Elements (see Box 1) } & \multirow{2}{*}{ Notes } \\
\hline & 1 & 2 & 3 & 4 & 5 & 6 & 7 & 8 & 9 & 10 & \\
\hline FP1 & & $\mathrm{x}$ & & $\mathrm{x}$ & $\mathrm{x}$ & $\mathrm{x}$ & & & & $\mathrm{x}$ & $\begin{array}{l}\text { Emphasis on future research } \\
\text { leaders }\end{array}$ \\
\hline FP2 & $\mathrm{x}$ & $x$ & & $\mathrm{x}$ & & & & & & $\mathrm{x}$ & $\begin{array}{l}\text { CapDev center stage, with } \\
\text { emphasis on training of } \\
\text { smallholders* }\end{array}$ \\
\hline FP3 & & $x$ & & & $x$ & & & & & $x$ & 8 commodities \\
\hline FP4 & & & & & & & & & & & $\begin{array}{l}\text { No CapDev elements. Focus on } \\
4 \text { sub-IDOs }\end{array}$ \\
\hline FP5 & & & & & $X$ & $X$ & & & & & $\begin{array}{l}10 \% \text { of budget for CapDev and } \\
\text { targets }\end{array}$ \\
\hline
\end{tabular}

Note:

* The CGIAR CapDev evaluation Recommendation \#3 states, "the CGIAR should aim at taking full advantage of the experience and facilities of the centers, particularly with regard to their scientific staff and amenities, and training of local end users and communities should be de-emphasized or channeled through more appropriate CD providers to ensure better relevance and focus and greater cost-effectiveness of CGIAR's efforts" (IEA, 2017a).

\section{Box 1. Key elements of capacity development}

1. Capacity needs assessment

2. Design and delivery of innovative learning materials and methods

3. Development of CGIAR Research Programs' capacity to partner

4. Development of future research leaders through fellowships

5. Gender-sensitive approaches throughout capacity development

6. Institutional strengthening

7. Monitoring and evaluation of capacity development

8. Organizational development

9. Research on capacity development

10. Quality control 
FP4 did not refer to any CapDev elements, but focused on four sub-IDOs (FTA 2017a).

FP5 focused on enhanced individual CapDev in partner research organizations, and on the coproduction of science and tools. Further, FP5 was the only flagship to set specific targets in terms of numbers of new master's and PhD students to be trained and to specify the budgetary support for CapDev activities.

\subsection{Partnerships within the FTA}

FTA is managed by CIFOR, in partnership with its managing partners: Bioversity International, the Tropical Agricultural Research and Higher Education Center (CATIE), the French Agricultural Research Centre for International Development (CIRAD), the International Network for Bamboo and Rattan (INBAR), Tropenbos International (TBI), and World Agroforestry (ICRAF), and links with a number of contributing partners. The contributing partners could be from research, practice or the private sector. For research, such partners may include various CRPs, in particular Climate Change and Food Security (CCAFS), Water Land and Ecosystems (WLE), Dryland Cereals and Legumes and Legumes (DCL), and Policy, Institutions and Markets (PIM). Governmental ministries form another type of contributing partners that are specific to certain flagships, or to projects in flagships, but not to the whole of the program. For example, ministries of environment and climate may be central partners to FP5; ministries of economics may be relevant to FP3, but not to the other FPs; ministries for land planning and environment for FP4; and ministries of agriculture and development for FP2. In fact, contributing partners could be characterized along two axes: from activity to program, or along the theory of change continuum.

CIRAD, CATIE, TBI and INBAR are four strategic partners supporting FTA II flagships that are not CGIAR centers. These institutions have mandates that move beyond research to include education (CATIE), environmentally sustainable development using bamboo and rattan (INBAR) and use of knowledge in the advocacy for the formulation of appropriate policies and in the management of forests for conservation and sustainable development (CIRAD and TBI). Both TBI and INBAR focus beyond production of international public goods towards development outcomes, and as such could also be considered as boundary partners. Formal capacity needs assessments may be needed to assist in identifying new future FTA partners engaged to manage or communicate research and/or ensure that research results are used by other actors.

The CGIAR Evaluation of Partnerships (CGIAR-IEA 2017d) identified only five CRPs with a purposively designed and documented strategy for partnerships, but acknowledged that "... partnerships have become a more explicit and prominent feature of Center strategy documents" (2017: 10), although most critical partnerships were established prior to CRPs or during the early CRP period (pp. 15-16 and Figure 3). The evaluation recognized that "... although most programs have not had a well-defined strategy with regard to partnerships models, they have been willing to work with a range of models to fit specific situations, and to experiment when necessary" (2017: 19). The evaluation team would have benefited from more extensive discussions on global multistakeholder platforms (e.g. Roundtable on Sustainable Oil Palm - RSPO, Global Shea Alliance - GSA, African Forest Landscape Restoration Initiative AFR100 and Initiative 20x20 in Latin America), especially those linked to climate change and landscapes, with a broader set of centers, including FTA, CIFOR and ICRAF. The partnership evaluation report also noted that "the low level, unreliability and late delivery of core funding..." "... have been damaging to partnerships." Further, "[f]unding uncertainty has created a disincentive to commit a falling core budget to the costs of investing in new partnerships or experimenting with new partnership models ..." (2017: xi). The recommendations put too much emphasis on CGIAR system-level interventions despite 
the report's skepticism over the system's capacity to either provide strategic direction or follow-up on earlier findings and recommendations (2017: 39-46).

FTA, in operationalizing its partnership strategies, uses a three-pronged approach to further strengthen partnerships: (i) better valuing partnerships as an essential component of the program itself and one of its important comparative advantages; (ii) securing long-term engagement with the program through increasing and deepening joint activities; and (iii) identifying and characterizing partnerships in order to identify areas where a partnership would be critical to fill a gap. 


\section{Methodology}

In line with the key focus of the study, to understand if cluster and flagship teams (together with their networked partners) have sufficient capacity to deliver on their respective theories of change and impact pathways as outlined in their write ups in the FTA final proposal, a two-part method was employed. Firstly, a detailed review of the theories of change was undertaken within each of the flagships. The purpose of the review was to allow benchmarking in the analysis of the responses from the interviews. This primary data collection, through semi-structured interviews (see Appendix 2 for interview list), was based on an analytical framework of key capacity areas, as shown in Table 2.

Table 2. Analytical framework for capacity assessment

\begin{tabular}{ll}
\hline Framework pillar & Description of capacity \\
\hline Expertise capacity & $\begin{array}{l}\text { Expertise implies the necessary skillsets and thematic backgrounds required to } \\
\text { achieve intended outcomes and outputs set out within each FP's TOC and within } \\
\text { the broader context of program needs for interdisciplinary novel research and } \\
\text { resource mobilization. The expertise capacity implies adequate research staff from } \\
\text { the required disciplines and with the necessary experience and qualifications to } \\
\text { produce the promised research outputs. }\end{array}$ \\
\hline
\end{tabular}

Partnering and networking capacities

Partnering and networking capacities imply the ability to identify, develop and maintain opportunities with important partners across the impact pathway, from research partners through to those involved in achieving development impacts. These are capacities for scaling up (e.g. within already defined locations) and scaling out (i.e. to new locations).

Outreach capacity links to staff being able to communicate and share products with boundary partners and networks in appropriate forms, and to leverage interactions.

Capacity to develop, manage and ensure effective partnerships is centered around flagships having strategic research partners for delivering outputs, including area expertise or location. In addition, the research is co-designed with those who use the research, thereby assisting in delivering outcomes, and ensuring that research planning is demand-driven and that outputs are readily used by boundary partners such as NGOs, platforms, government (extension and research), community-based organizations, etc.

Capacity to mobilize financial resources

This involves having a strategy (at the flagship level) to acquire the resources required for achieving TOC outputs and outcomes. In general, the FTA proposal states that the resource mobilization strategy is to cover the existing shortage in financial resources through bilateral projects; and the adaptation strategy, in case the mobilization strategy is not fully successful, is to reduce the scale and scope of activities.

Managerial capacities Managerial capacities at cluster and flagship levels imply the ability to perform on set outputs and outcomes. These capacities will be analyzed based on the assessment of partnership and outreach/communication capacities.

Using the framing of the analytical framework, an interview guide (Appendix 3) was developed for the study. The guide covers key pillars of the analytical framework and leaves openly structured space for probing additional enabling factors not categorized under the analytical framework. A structured approach to the interview schedule was applied, with FP leaders interviewed first, followed by cluster 
leaders and then partners. The technique of snowball sampling, whereby interviewees were asked to suggest further pertinent personnel to be interviewed, was applied. Sixty-six semi-structured interviews were carried out across the five FTA II flagship programs, as well as with the SMO and other CGIAR Research Programs, strategic/boundary partners, National Agricultural Research System (NARS), young FTA II scientists, development partners, and networks; the interviews also focused on specific topics (e.g. communications) within FTA. Interviews were conducted in person and online through Skype between November 2017 and June 2018, lasting on average one hour in duration. Interviews were analyzed using the analytical framework to group responses and a simplified coding structure to identify commonalities and differences within each pillar of the framework. Qualitative methods (induction, comparison of the insights from different interviewees, categorization and generalization) were applied in the analysis of the interviews. Cross-comparison and discussion of results was carried out, and a third party was engaged if any debate occurred in the analysis process. 


\section{Results}

\subsection{Structure of findings}

The findings and key recommendations from the capacity assessment are presented in line with the analytical framework, with key study findings based on the framework pillars. Additional analysis was carried out on specific capacity needs of strategic managing partners, so the networking and outreach capacity pillars are presented in separate sections of the results. The results section is structured as a summary of key insights and discussion from the interviews, under the following headings:

- Expertise capacity

- Partnering and networking capacities

- Learning across FTA II research partners

- Partnership strategy

- Network of partners to deliver on the TOCs

- Capacity development of national research partners

- Integrating research in development

- Capacity for outreach, collaboration and capacity building of partners

- Capacity to mobilize financial resources

- Managerial capacities

Insights and recommendations follow the results section.

\subsection{Expertise capacity}

With diverse outputs expected from the FPs, a unique combination of disciplinary backgrounds and experience are needed for each FP and CoAs. Respondents were asked if they felt the FP they were linked to had research staff from the required disciplines and with the necessary experience and qualifications to produce the promised research outputs. Across all FPs, respondents felt that overall there was capacity to deliver on the research outputs, and where gaps existed, partnerships across CGIAR, with universities and other managing research entities able to fill them. In some FPs, such as FP3 and FP5, the critical mass of senior scientists was considered lacking. Some discipline gaps were recognized as important to fill, but because they were internal to the institutions they will not be discussed here.

An area of concern that emerged clearly across the FPs was that the capacities of different centers were not always being utilized effectively; many felt that, especially in light of FTA II's restricted budgets, a coordination mechanism for skill sharing is needed. For example, respondents from FP2 expressed that CIFOR has greater social science expertise that is not fully utilized in the FPs, and that CATIE has a comparative advantage in Latin America, especially on liaison, partnership establishment, formal and informal training and communication with national governments; these could be valuable skills to share and leverage.

In January 2019, CIFOR and ICRAF merged. This merger was immediately operational, with a common Board of Trustees and a single leadership team. The two centers are working towards unified policies and systems to be able to more comprehensively provide the evidence and innovative solutions needed to scale up investment in rural sustainable development and address global challenges. The new global institution will focus on sustainable and equitable land use, innovative finance, and performance landscape management with an integrative 'research-development-policy-investment-delivery' mode 
of operating. The ongoing merger process between CIFOR and ICRAF will reinforce the need to more effectively harness the different capacities of the two centers.

Key recommendations for enhancing skill sharing to address this gap are:

- A capacity inventory and associated opportunities to enhance or access capacities through networks should be completed by the human resources team, in collaboration with capacity development or communications focal points in FPs.

- Establish an online portal where staff biographies, skillsets and interests are shared (proposed by a respondent from FP4). This portal would link people in networks or communities of practice on common interest topics. This could either be housed on the institutional websites or internally as an intranet function, or be curated via social media channels such as an internal Facebook or WhatsApp groups.

\subsection{Partnering and networking capacities}

The partnering and networking capacities are unique to each context. For example, networks of research and boundary partners that are present and lead to success (outputs and outcomes) in country A are not necessarily present and lead to success in country B. This assignment explored the interviewees' assessment of contextual specificities of partnering and networking capacities within each FP and cluster.

\subsubsection{Learning across FTA II research partners}

The FTA proposal focuses on flagships as interdependent (FTA 2017a). FTA uses various avenues for interfacing and coordinating between FPs, including: (i) various FPs working on the same commodities (e.g. timber, cocoa, oil palm) from diverse entry points and impact pathways; (ii) co-location of activities in Sentinel Landscapes; (iii) co-location of research activities in site integration countries; (iv) identification of emerging themes (e.g. eco-labeling or certification) that concern several FPs; and (v) bilateral projects connecting work across multiple FPs in a given geographical context. The structure allows FPs to work both as stand-alone units and coherently with each other, building on each other's work, as also exemplified in the contribution to FTA II targets.

In 2018 a new priority-setting process was introduced in FTA to promote focus, alignment and coherence of all proposed activities as a mechanism to work across disciplines and across flagships. The priority setting was also intended to streamline and improve transparency and inclusiveness of the planning process, and to provide a unified framework and a set of guidelines, to help organize discussions on work plans and on the best use of W1/W2 and bilateral resources. The process was crafted collectively by FTA Senior Management (FTA Director, FP leaders, Monitoring, Evaluation, Learning and Impact Assessment (MELIA) Leader), under the oversight of the FTA Independent Steering Committee (ISC), which requested that FTA develop such a procedure, approved it and subsequently approved its results.

Twenty-five operational priorities ${ }^{2}$ were identified through this process (see Appendix 1), leading to increased focus on priority areas for W1/W2 and bilateral/W3 investments to implement FTA's theory of change. These priorities address, within the framework of the proposal, important development demands and knowledge gaps, and are oriented towards the implementation of the SDGs and the Paris Climate Agreement. They build on the comparative advantages of FTA and its partners in order to maximize effectiveness and impact.

2 In FTA, an operational priority is defined as: "a coherent and focused set of works/activities (funded by bilateral projects or funded by W1/W2 ) whose outputs aim at answering one or several key knowledge gap(s), and whose outcomes are directed to respond to a major development demand/challenge, building on the comparative advantage of FTA and its partners, and aiming at maximizing the effectiveness and impact of FTA". 
The operational priorities ${ }^{3}$ are articulated in the following way: the ultimate outcomes at household level of enhanced nutrition and food security and improved livelihoods, including gender $(3,10,15)$ are supported by action in farming systems: silvo-pastoral systems, market-based agroforestry, forestry systems, farm-forest policy interface, agroecology, plantations and tree crop commodities $(2,11,12,13,14,24)$ and by coordinated action along value chains: inclusive finance and business models, innovating finance for sustainable landscapes, public and private commitments to zero deforestation, effectiveness of approaches to sustainable supply like certification and standards for Forest Law Enforcement, Governance and Trade - FLEGT $(16,17,18,20)$. They rely on the provision of appropriate genetic material at scale with support to tree seeds and seedlings delivery systems, and on sustainable management of natural resources: land and forest restoration, biodiversity, safeguarding and conservation of genetic resources, orphan crops, and landscape governance (1, 4, 9, 19,25). They fully address climate change and implementation of the NDCs (both adaptation and mitigation), including zero deforestation, bioenergy, blue carbon and peatlands $(5,6,7,8,18)$. Three operational priorities - ensuring the quality of FTA research for development (21), monitoring a set of Sentinel Landscapes (22), and conducting foresight (23) - aim to identify emerging trends and possible futures for forests, trees and agroforestry systems, and their roles for broader sustainable development objectives.

A consistent response during the interviews was that FTA II had not delivered on its ambition of creating more cross-center collaboration, and that this is particularly apparent with respect to joint fundraising. The benefits of co-locating CGIAR center offices has promoted collaboration in some cases, but in others it has done little (perception from a respondent from FP2). Much of the collaboration was consistently reported to be based on personal relationships. The lack of clear communication mechanisms or incentives for cross-sectoral and interdisciplinary approaches or collaboration was highlighted as a contributing factor by one respondent from FP4. It was acknowledged that there is a process underway to develop integrated projects across FPs, and respondents were waiting to see the outcome of this. Some other initiatives intended for learning, such as the Sentinel Landscapes, were seen by some respondents from FP4 as not having reached their potential.

Recommendations to enhance cross-center collaboration include:

- Enhance interaction of staff across centers.

- This could be achieved through establishing clear communication and formalized interactions, both in person and virtually. "Dynamic opportunities for structured but informal interaction" (FP2 respondent) such as an additional day following planned events like retreats and annual meetings, or through webinars on common topics across partner organizations. Other opportunities include cross-center collaboration to summarize cross-cutting work (e.g. FP1 respondent proposed commodity based agroforestry systems across the globe). A recent example is CIFOR's palm oil 'folder' comprising 11 Infobriefs based on research conducted over two years and presented at the Innovation Forum smallholder event in London, in early 2018. Such efforts would have to involve multiple centers and partners.

- "An FTA webinar every six weeks to discuss and engage on the science not the management, possibly using the BlueJeans platform" (FP1 respondent).

- "Co-location of research staff can be extremely beneficial when it is utilized for collaboration or fundraising" (FP2 respondent). This was particularly highlighted in terms of support for interns and students.

- "Facilitating integration between flagships in geographic specific locations like Sentinel Landscapes (FP4), with greater focus on the learning opportunities" (FP4 respondents).

3 Numbers in parenthesis refer to the operational priorities in the list (Annex 1), with no significance of the order. 
- Facilitating integration between flagships in geographic specific locations like Sentinel Landscapes (FP4), with greater focus on the learning opportunities (recommended by FP4 respondents).

- Incentive structure for cross-center working relations and interdisciplinary approaches was mentioned by many respondents. These incentives could be in the form of performance review recognition of collaboration.

\subsubsection{FTA Partnership Strategy}

Partnerships are critical to achieving research outputs and outcomes at scale for FTA. Co-designing, implementing and delivering FTA research together with partners enhances FTA's internal capacity to generate demand-driven and relevant research results. Participating in creating salient, credible and reliable research results further strengthens the outreach partner's capacity to disseminate research findings (FTA Partnership Strategy).

The FTA Partnership Strategy considers partners to be strategic and long-term 'allies', e.g. organizations that share the FTA vision and mission and are willing to contribute their own resources to achieving the mission. Partners bring complementary research and development skills and/or outreach opportunities that may otherwise be lacking within the FTA team. Based on their strengths and interests, partners have defined roles to play that contribute to achieving FTA's intended outcomes. Partners have mutual accountability to each other and to the mission of FTA. Thus, collectively, the FTA partners are able to influence thinking, practice and attitudes of decision-makers at various levels. Service providers are project/grant-specific organizations or individuals (i.e. consultants) that are subcontracted for a limited duration to perform one or more defined tasks. Service providers can be engaged and disengaged based on FTA's changing needs and opportunities in the external environment.

Partners play a key role in impact pathways, i.e. in moving from research outputs to research and development outcomes. The aim of various partnerships may include one or more elements of: achieving excellence in research and scientific capacity development (discovery); testing and adaptation of concepts, tools and management options (proof of concept); and scaling (policy advocacy, advice and/or influence and developmental implementation).

FTA differentiate two levels of partnerships: managing and contributing. Managing partners are closely involved in design, management and governance as part of FTA's management team. They co-invest in shared impact pathways, working together at discovery, proof-of-concept and scaling levels. They have been continuously involved in strategic and operational decision-making during FTA II. FTA's managing partners are CIFOR, ICRAF, Bioversity, CATIE, CIRAD, TBI and INBAR. The inclusion criteria for managing partners were: (i) interest in partnering; (ii) relevance and criticality to achieving FTA mission; (iii) degree of alignment of partner's mandate, vision and mission with FTA agenda; (iv) complementarity of expertise and geographical coverage; ( $v$ ) potential for joint and/or aligned bilateral resources mobilization; and (vi) potential for sustaining the partnership.

In contrast, contributing partnerships have important but more specific roles. They may be limited to a single geography, commodity/value chain or a single research cluster. FTA's contributing partners participate in implementation and management of their own activities/roles related to FTA but not in the overall management or governance of FTA. They are involved in the design and implementation of various COAs under various flagships. Examples include: CCAFS, WLE, DCL, PIM, IUCN, SEI and IIASA and other partners that are specific to certain flagships, or to projects in flagships, but not to the whole of the program. Examples in FP3 include the Global Shea Alliance (GSA) in West Africa and the Table Filière Karité (TFK) in Burkina Faso. Contributing partners can be from research, development or the private 
sector. Donors that are engaged in FTA with a long-term perspective share numerous characteristics and interests with these partners, as "funding partners".

A typology with the roles of various partnerships is presented in Annex 3.2 of the FTA Phase II proposal (FTA 2017b).

FTA has qualified scientists and achieves impact at the international level (e.g. cumulative impacts of FP5, FP4, the Global Landscapes Forum and its predecessor'Forest Day' on the international negotiations on climate change). However, one strategic partner respondent suggested it has less impact at the national level (and even less at subnational levels of governance), as project timeframes are short and many researchers focus on research outcomes. This gap is where the role of partners, and synergies with key new strategic and contributing partners, are essential. Recent research by FP3 and FP5 on jurisdictional approaches to promoting sustainability in agricultural and forest commodity value chains and on REDD+, respectively, has assisted in exploring new partnerships with, for example, the Sustainable Trade Initiative (IDH) and World Wildlife Fund (WWF).

Existing FTA managing partners have the following coverage:

- Tropenbos International (TBI) currently operates country programs in Colombia, Democratic Republic of the Congo, Ghana, Indonesia, Suriname and Viet Nam. Under the Green Livelihoods Alliance, TBI participates in projects in Bolivia, Liberia, Nigeria, Uganda and the Philippines. Additionally, TBI participates in a project in Honduras. These country programs give TBI a long-term presence, and build trust and connections in the national forest arena. TBI forms networks between researchers, policy makers and practitioners, and between national and international partners, supported by an agreement with a government ministry responsible for forests or the environment.

- INBAR is an intergovernmental organization of 43 Member States working in Asia, Africa and Latin America. CIFOR partnered with INBAR in the Democratic Republic of the Congo to develop technical guidelines to propagate bamboo for both habitat restoration (for mountain gorillas) in the Virunga National Park and as a source of income for poor rural communities living around the park. The guidelines were published in English, French and Kiswahili.

- CATIE has 14 member countries in Latin America and has a unique combination of science, postgraduate education, outreach and innovation for development. CATIE has more than 45 years of promoting landscape approaches in Latin America and the Caribbean.

- CIRAD works in more than 90 countries for the sustainable development of tropical and Mediterranean regions.

Considering the distribution of managing partners' activities (Figure 1), the region with less coverage, particularly when looking beyond rattan and bamboo, is sub-Saharan Africa. One managing partner indicated that the composition of partners is good, but questioned if there are perhaps too many partners linked to FTA projects if they are to be mobilized effectively. The multiple demands on one managing partner working across several flagships (FP3, FP4 and FP5) may also be unrealistic, given existing capacities. This is compounded by the limited breadth and depth of CGIAR center staff working in some flagships such as FP3, and an extremely limited FTA Phase II budget for CapDev as one of a number of cross-cutting themes. As one observer noted, "[W]ith no CGIAR funding left (for the CapDev COP), it is not worth investing in collective action with derisory budget allocations" (interview with ILRI representative, former Chair of the CGIAR CapDev COP, Nairobi, 23 April 2018).

Recommendation: A review of the managing partners, their geographical and institutional focus, and their personnel capacity should take place and could provide valuable insight into understanding if the current composition of FTA managing partners is sufficient to deliver on the FP's respective TOCs. 


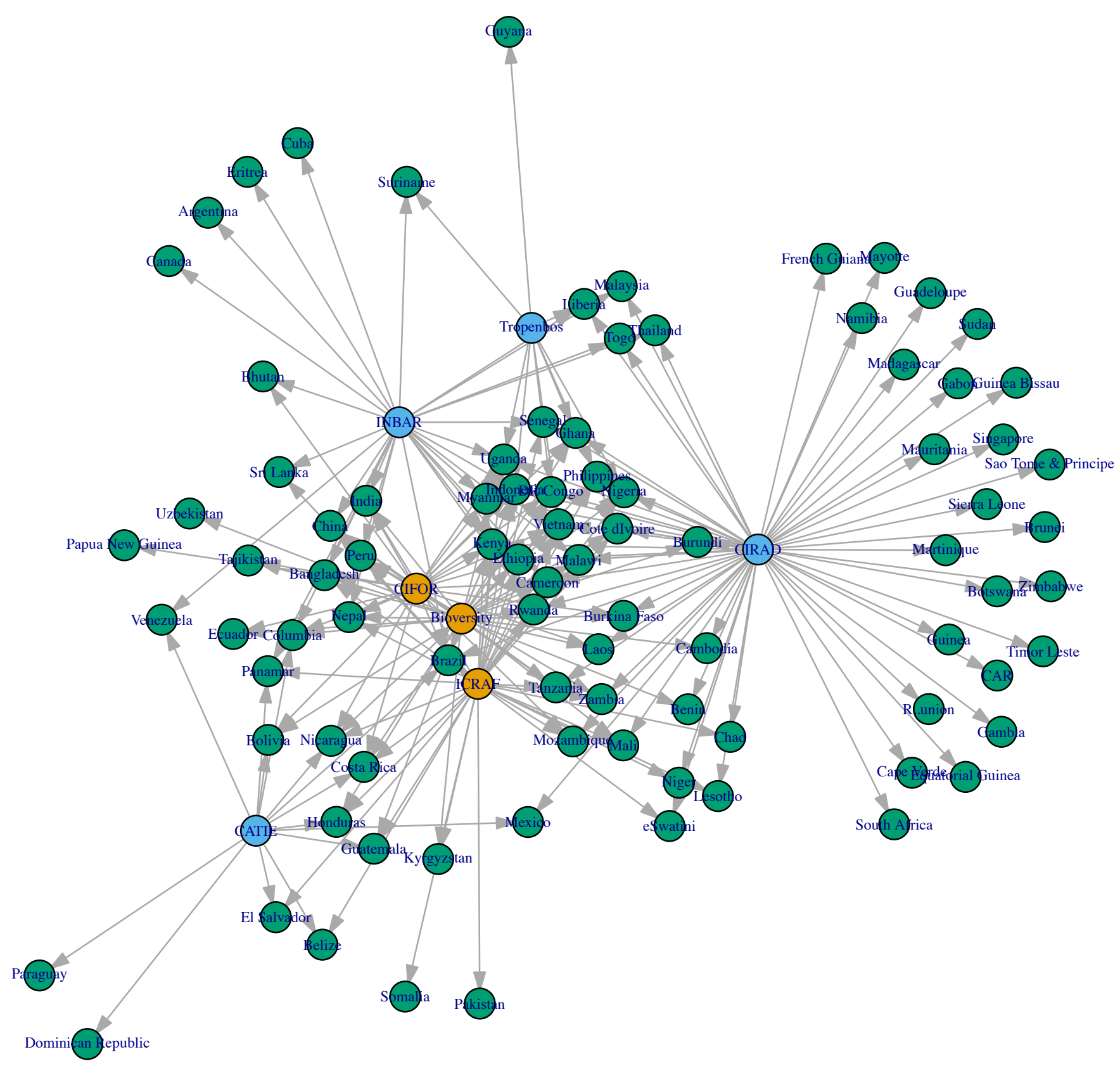

Figure 1. Sociogram showing FTA's managing partners and the countries in which they conduct activities

Note: Orange $=$ CGIAR centers; blue $=$ strategic partners; green $=$ countries

Two FTA managing partners identified three key areas for strengthening and/or capacity development:

1. Internal communication. FP focal points could enhance interaction with managing partners and provide clear communication on expectations for partners (particularly FP2).

2. Creating a common vision. FTA needs to develop a strong, clear, synthetic and common vision that considers both objectives and substance, to share with donors and all managing partners.

3. Focusing on impact. FTA needs an institutional strategy on how to extend research outputs and knowledge to partners, so that the responsibility is not left to partners but is the job of all scientists to achieve outputs and allocate budgets for this work. 
Recommendation: integration of capacity development questions into the TOC for the development of new projects and programs, to achieve a focus on impact.

Recommendation: enhanced capacity in science communication, either through consultants or enhanced internal capacity, is needed.

Learning from past efforts in achieving impact, through tracer and outcome studies, would also be useful, as would the use of new technologies such as Linkedln for all CapDev/training activities to make it easier to follow up with students and trainees.

\subsubsection{Network of partners to deliver on TOCs}

It is clear that functioning partnerships are key for all FTA flagships to deliver on their TOCs. As recognized by one FP4 respondent, "an institution itself doesn't need all the skills and capacity to do the impact work themselves, but can achieve this by partnering".

Often, researchers do not have access to the necessary networks and/or possess the capacity to reach intended end-users. Therefore, FTA will partner with various contributing partners. Following the approach of Outcome Mapping, these have been specified for each FP (see ToC section for each FP) and will be further refined at the project level. As described in Annex 3.6, much of FTA Il's MELIA efforts will focus on monitoring and reviewing the behavior of all boundary partners (including FTA Il scientists) against expected progress markers. (FTA 2017a)

One FP4 respondent observed, "an institution itself doesn't need all the skills and capacity to do the impact work themselves but can achieve this by partnering". It is clear that functioning partnerships are key for all FTA flagships to deliver on their TOCs.

FTA flagships work with governments, private companies and NGOs to achieve impact. Table 3 provides examples of partners for FPs 1, 2, 3, 4 and 5, as outlined in the FTA II flagship proposals. Partners fall into six broad, overlapping categories: private sector, development and conservation actors, government, intergovernmental and research. The partnerships are likely to change over time and, while some are long term and linked to FPs, others are engaged on specific, often bilateral, projects or through particular or historical relationships between scientists.

Within each FP theory of change, and as highlighted through interviews, each FP, while working through multiple types of partners, places emphasis on different partner categories. FP2 works extensively with development actors to achieve outcomes at scale, while FP4 has a strong emphasis on subnational governance, and FP1 works extensively with the private sector and conservation organizations. FP3 and FP5 both work with a broad array of research, development, outreach and communications partners. The CIFORled Global Landscapes Forum provides an extremely valuable mechanism to present research findings, by convening large numbers of actors engaged in e.g. climate change negotiations or innovations in finance.

Interestingly, donors were not listed as partners in the proposal documents. There is an opportunity to work more closely with donors to develop proposals that do not have to respond to a call. CIFOR has completed the 7-pillar assessment for the European Commission (EC), and ICRAF is investigating this possibility, which provides one avenue to develop proposals directly with the EC without having to wait for public calls-for-proposals.

Working with the private sector presents a number of opportunities for CGIAR centers, but such partnerships are still limited in number across FTA II flagships. An example of successful engagement with the private sector is presented in Box 2. 
Table 3. Examples of important partners for FPs 1, 2, 3, 4 and 5, as outlined in the FTA Phase II proposal

\begin{tabular}{|c|c|c|c|c|c|}
\hline $\begin{array}{l}\text { Partner } \\
\text { category }\end{array}$ & FP1 & FP2 & FP3 & FP4 & FP5 \\
\hline Private sector & $\begin{array}{l}\text { Mars Inc., Nestlé and } \\
\text { Unilever (global and } \\
\text { regional) } \\
\text { SMEs and organized } \\
\text { farmer groups (local) }\end{array}$ & $\begin{array}{l}\text { Mars Inc. in Côte } \\
\text { d'Ivoire; Natura in } \\
\text { Brazil (large scale) } \\
\text { National SMEs } \\
\text { (co-develop novel } \\
\text { products) }\end{array}$ & $\begin{array}{l}\text { SAN, FAST, } \\
\text { RSPO, GASCA, } \\
\text { FSC, TFA 2020, } \\
\text { ISEAL, IDH, } \\
\text { Profundo }\end{array}$ & $\begin{array}{l}\text { Private } \\
\text { sector actors } \\
\text { mentioned in } \\
\text { TOC }\end{array}$ & $\begin{array}{l}\text { Danone } \\
\text { Livelihoods } \\
\text { Fund, } \\
\text { Indonesian } \\
\text { Estate Crop } \\
\text { Fund, RSPO }\end{array}$ \\
\hline $\begin{array}{l}\text { Development } \\
\text { (NGOs) }\end{array}$ & $\begin{array}{l}\text { Development NGOs } \\
\text { including Concern } \\
\text { Worldwide, Vi- } \\
\text { Agroforestry and } \\
\text { World Vision }\end{array}$ & $\begin{array}{l}\text { IFAD, World Vision, } \\
\text { Vi-Agroforestry, } \\
\text { One Acre Fund, } \\
\text { CARE and } \\
\text { SahelEco }\end{array}$ & $\begin{array}{l}\text { Centro Terra } \\
\text { Viva, SPDA, } \\
\text { SNV }\end{array}$ & $\begin{array}{l}\text { The } \\
\text { Landscapes } \\
\text { for People, } \\
\text { Food and } \\
\text { Nature (LPFN) } \\
\text { network of key } \\
\text { development } \\
\text { partners }\end{array}$ & CODELT, SEI \\
\hline Conservation & $\begin{array}{l}\text { Regional and global } \\
\text { levels, including } \\
\text { APFORGEN, } \\
\text { LAFORGEN, } \\
\text { CacaoNet, COGENT, } \\
\text { INGENIC and } \\
\text { ICCO, Global Tree } \\
\text { Assessment- } \\
\text { Botanic Gardens, } \\
\text { Conservation } \\
\text { International and } \\
\text { the IUCN Global Tree } \\
\text { Specialist Group }\end{array}$ & WWF & $\begin{array}{l}\text { WWF, TNC, } \\
\text { IUCN }\end{array}$ & $\begin{array}{l}\text { IUCN, WWF, } \\
\text { TNC } \\
\text { The Ibero- } \\
\text { American } \\
\text { Model Forest } \\
\text { Network }\end{array}$ & $\begin{array}{l}\text { TNC, GFW, RRI, } \\
\text { IMC, IPAM }\end{array}$ \\
\hline Government & $\begin{array}{l}\text { Government } \\
\text { agencies including } \\
\text { treaty-competent } \\
\text { authorities } \\
\text { Government } \\
\text { extension services } \\
\text { National tree seed } \\
\text { centers }\end{array}$ & $\begin{array}{l}\text { Ministries of } \\
\text { Environment and } \\
\text { of Agriculture in } \\
\text { Peru, EMBRAPA in } \\
\text { Brazil } \\
\text { High level } \\
\text { policy platforms } \\
\text { for national } \\
\text { agroforestry policy } \\
\text { (Ethiopia, Uganda } \\
\text { and Rwanda), } \\
\text { Local governments } \\
\text { (Vietnam, Kenya) }\end{array}$ & $\begin{array}{l}\text { TBI links with } \\
\text { governments } \\
\text { National and } \\
\text { subnational } \\
\text { governments } \\
\text { in prioritized } \\
\text { landscapes }\end{array}$ & $\begin{array}{l}\text { TBI links with } \\
\text { governments } \\
\text { National and } \\
\text { subnational } \\
\text { governments } \\
\text { central to TOC }\end{array}$ & $\begin{array}{l}\text { Ministries of } \\
\text { Environment/ } \\
\text { Forestry in } \\
\text { e.g. Indonesia } \\
\text { Vietnam and } \\
\text { Peru }\end{array}$ \\
\hline $\begin{array}{l}\text { Inter- } \\
\text { governmental }\end{array}$ & $\begin{array}{l}\text { FAO, CBD and the } \\
\text { secretariats of the } \\
\text { International Treaty } \\
\text { on Plant Genetic } \\
\text { Resources for Food } \\
\text { and Agriculture and } \\
\text { the Nagoya Protocol, } \\
\text { with national focal } \\
\text { points in target } \\
\text { countries, OECD }\end{array}$ & & $\begin{array}{l}\text { FAO, UNDP, } \\
\text { UNEP-FI, IFC, } \\
\text { WB and GASCA }\end{array}$ & & $\begin{array}{l}\text { Governor's } \\
\text { Forests and } \\
\text { Climate Task } \\
\text { Force } \\
\text { UNFCCC-COP/ } \\
\text { SBSTA/ } \\
\text { Paris WG } \\
\text { Adaptation } \\
\text { Board } \\
\text { IPCC }\end{array}$ \\
\hline
\end{tabular}


Table 3. Continued

\begin{tabular}{|c|c|c|c|c|c|}
\hline $\begin{array}{l}\text { Partner } \\
\text { category }\end{array}$ & FP1 & FP2 & FP3 & FP4 & FP5 \\
\hline Research & $\begin{array}{l}\text { Forestry and } \\
\text { horticultural } \\
\text { research centers and } \\
\text { foundations such as } \\
\text { the World Vegetable } \\
\text { Center and the } \\
\text { International Tree } \\
\text { Foundation (ITF), } \\
\text { public and private } \\
\text { breeders, and regional } \\
\text { research hubs such as } \\
\text { BECA. UC Davis (USA), } \\
\text { JHI (UK), University of } \\
\text { Copenhagen, WRI }\end{array}$ & $\begin{array}{l}\text { NARES, } \\
\text { Universities, } \\
\text { colleges and } \\
\text { schools identified } \\
\text { in TOC }\end{array}$ & $\begin{array}{l}\text { SEI, IIASA, } \\
\text { Copernicus } \\
\text { Institute of } \\
\text { Sustainable } \\
\text { Development, } \\
\text { RFF, ISL- } \\
\text { Cambridge } \\
\text { National } \\
\text { universities } \\
\text { including UPM, } \\
\text { IPB }\end{array}$ & $\begin{array}{l}\text { Cornell } \\
\text { University } \\
\text { and CDI } \\
\text { (Wageningen) } \\
\text { Ecosystem } \\
\text { Services } \\
\text { Partnership } \\
\text { (ESP). } \\
\text { WRI, SEI, IIASA }\end{array}$ & $\begin{array}{l}\text { Universities in } \\
\text { USA, Norway, } \\
\text { Finland, } \\
\text { Netherlands, } \\
\text { UK, Germany } \\
\text { and many } \\
\text { developing } \\
\text { countries } \\
\text { including } \\
\text { Indonesia, } \\
\text { Vietnam, Peru } \\
\text { INBAR } \\
\text { IIASA }\end{array}$ \\
\hline
\end{tabular}

Box 2. Private sector engagement: the case of Mars Inc.

ICRAF has been working in partnership with Mars Inc. to improve the yields and profits of smallholder cocoa producers in Côte d'Ivoire since late 2010. ICRAF began its relationship with Mars Inc. through a small project won on the basis of a competitive tender. Over time, the collaboration has deepened to the development of a comprehensive private-public partnership, Vision for Change: Building Sustainable Cocoa Communities. Through this partnership, research on remunerative cocoa landscape rehabilitation for improved farms productivity, profitable returns and sustainable environmental health, securing markets for agroforestry products and quantifying the role of trees on farm for climate change mitigation and adaptation takes place. Development of the national cocoa system has been the focus of the collaboration, making the project outputs publicly available and ensuring development outcomes are central and come first, with room for research and testing of options. A number of factors are recognized as key to ensuring success:

- Develop and maintain trusted relationships, including between focal points in both organizations.

- Test options for the development-oriented agenda of the donor and show off successes/challenges to donors and key stakeholders.

- Start small and build a shared understanding to tackle more complex and system-wide challenges in the cocoa production and marketing system.

- Build strong relationships and a shared platform with local governments, key stakeholders and partners to ensure their participation, ownership and sustainability.

Source: Christophe Kouame, ICRAF Regional Director for West and Central Africa

It is not possible to identify if the optimal partner mix has been achieved by each FP, as many of the partners change, based on bilateral projects. It is however important that the FPs and FTA II overall are actively responding to partners' needs and are able to interact with and deliver the required research outputs in a timely and productive fashion.

Some of the methods used by researchers in the FPs to identify appropriate stakeholders include the use of stakeholder mapping and analysis in FP2, and discussion with ministries followed by a rigorous criteria-based selection process for FP4. 
Respondents from FP4 criticized the FTA partnership model as 'business as usual', and suggested that a nimbler partnership model is needed, including diverse partners. Such a model may include strategic and long-term partnerships combined with engagement with new partners as needed, perhaps through multistakeholder platforms.

However, a more focused approach to partnerships could be beneficial for FTA. The focus could differ by FP, and concern specific geographies. By focusing at the subnational level and working with key institutions such as local governments, efforts may be more influential and sustainable.

Demand-driven capacity development and multistakeholder engagement processes, such as the Stakeholder Approach to Evidence and Risk Informed Decision Making (SHARED) methodology, provide a tailored approach to aiding decision-makers (see Box 3).

Opportunities to expand the partnerships of the FPs to deliver on the TOCs exist; these include conservation and development organizations and new multistakeholder platforms, such as the Global Shea Alliance, headquartered in Accra, Ghana and the Table Filiere Karite in Burkina Faso.

\section{Box 3. Evidence-informed decision making at the subnational level - The SHARED methodology in Turkana County, Kenya}

The Stakeholder Approach to Evidence and Risk Informed Decision Making (SHARED) is a specialized decision hub based at ICRAF, with core functions to deliver tailored negotiation and decision support on the interaction between research, practice and policy. SHARED has developed a specialized methodology for evidence-based decision making, applied to specific decision cases. SHARED practitioners from ICRAF have established a long-term relationship with the Turkana County Government in Kenya and the decision case represents an example of the value of long-term relationship building to integrate research into policy processes. It started through a United States Agency for International Development (USAID) program on resilience in 2014. SHARED practitioners targeted relationship building within the Ministry of Finance and Planning, with a key mandate to work across sectors. SHARED acted as a coordination hub and neutral broker to convene meetings between agencies, align partners with their work on resilience, and help to simply translate key facts and recommendations for the Ministry of Planning. The success of this earlier partnership resulted in the SHARED methodology for evidence-based planning being used as the guiding framework for the development of the second iteration of the County Integrated Development Plan (CIDP). This resulted in SHARED practitioners acting as technical partners within the Ministry, helping to guide the review of progress and to structure an inclusive and evidence-based modality for the new CIDP II 20182022. Through guiding templates, informational material, workshops and facilitated working groups and convened meetings, the county government was taken through a facilitated process, with transformational changes integrated in the approach to planning. This included the establishing of benchmarks and evidence requirements to justify programs and budgets, sectors linking operational targets, and contributing joint budgets to develop integrated flagships project. This was endorsed through the capacity of the Ministry of Planning in taking a systems and cross-sectoral approach to development planning.

Key reflections from this include the importance of building authentic relationships and trust among policy makers and government structures to allow an entry point for key research and recommendations to inform budgetary decisions. In addition, acting as a technical backstop with regular communication channels, such as WhatsApp communication, allowed SHARED practitioners to be adaptive and rapid in their responses and to capitalize on political momentum. In addition, a sentiment of commitment to change, meaning continued relationship building outside of funded projects, is required to sustain relationships. 


\subsubsection{Capacity development of national research partners}

One of the key roles of CGIAR centers should be the scientific capacity development of staff from national research organizations. One FP4 respondent in this study identified that a significant gap in the FTA partnership structure exists for national institutions. While national institutions (NARS) are mentioned in each FP theory of change, their role is not prominent; this may be a gap in terms of sustainability, particularly if other partnerships developed through bilateral projects change between projects. Leeuwis et al. (2017) suggest that the best way to blend the international science and local development objectives of CGIAR is in the capacity development of national institution staff. The authors propose that capacity development can be achieved through postgraduate opportunities for national organization staff (Leeuwis et al. 2017), a sentiment echoed in the interviews undertaken in this study, as outlined in feedback from two NARS in Kenya and the Regional Universities Forum for Capacity Building in Agriculture (RUFORUM).

\section{Insights from two NARS in Kenya}

The Kenya Agricultural and Livestock Research Organization (KALRO) leads agriculture and livestock research at the national level. The key role of CGIAR centers in supporting KALRO was to development capacity in new methods and approaches among staff. The capacity to share or provide assets and resources and the ability to raise resources were also considered important. In the past, agreements have been seen to favor the CGIAR centers over the NARS, but as national governments move more towards loan programs for agricultural development, the CGIAR centers need to determine how they can support NARS or provide services as consultants. The CGIAR must support national research and development priorities and should train national staff to complete the research while they backstop it.

The Kenya Forestry Research Institute (KEFRI) undertakes research in forestry and allied natural resources. CGIAR centers such as ICRAF had greater interaction with KEFRI in the past when they implemented projects collectively and engaged in exchanges and conferences regularly. The memorandum of understanding between KEFRI and ICRAF needs to be renewed with a review of scope of interaction, given the new operating and policy environment. Opportunities for engagement include joint publications, exchanges and attachments between the two institutions, and enhanced information sharing. ICRAF can support KEFRI in terms of software, platforms and information and communication technology, as well as communications. An opportunity for KEFRI is that ICRAF is an international organization with access to international programs and resources and a track record with donors. KEFRI would benefit from collaborating with ICRAF to work on upscaling extension and best practices, and being engaged in international and regional projects.

\section{Universities and networks}

The Regional Universities Forum for Capacity Building in Agriculture (RUFORUM) has collaborated with a number of FTA centers and common networks, such as the African Network for Natural Resource and Agroforestry Education (ANAFE) and the African Women in Agricultural Research and Development (AWARD). RUFORUM as an African network is overseen by the universities, which provide insight into gaps and needs and ensure it is demand-driven. CGIAR centers can support African universities in three key areas: (i) through the use of facilities such as laboratories and equipment with associated technical experts; (ii) by providing scientific expertise through linking students to projects; and (iii) through long-term support to build national capacities in challenging contexts. This is exemplified by CIFOR's assistance to the University of Kisangani in the Democratic Republic of the Congo (Box 4). FTA could codevelop research programs with RUFORUM to enhance efforts for student placements, internships and 


\section{Box 4. Improving governance by building capacity in the Democratic Republic of the Congo}

University education suffered greatly during the periods of civil war in the Democratic Republic of the Congo (DRC), exacerbated by underfunding of the sector. This context changed a decade ago as the government initiated sectorial reforms and developed a clear vision of strategic research priorities. The country boasts the world's second largest area of contiguous tropical forests, which are distinguished by their rich biodiversity. In 2005 the country's entire forestry research cadre boasted just six people with a master's degree. A long-term capacity building program with the Faculty of Sciences at the University of Kisangani (UNIKIS), Tshopo Province - supported by the EC with CIFOR as the key implementing partner - included using novel teaching methods, development of new master's-level curricula materials and an electronic library, joint local and international supervision of students, an annual Science Week in tandem with a media training event, training UNIKIS staff and article-based theses. A local 'accompanying committee' tracked student progress and helped to develop scientific writing skills, resulting in the submission of more than 40 articles to international peer-reviewed journals, and the creation of the national Green Journalists' Network. UNIKIS has emerged as DRC's leading higher education institution on sustainable natural resource management. The Ministry of Higher Education has since adopted the 'Science Week' model for all universities and faculties in the country.

Source: CIFOR 2015

sabbaticals. Short-term sabbaticals of university staff within CGIAR centers could provide an opportunity for capacity development and strengthen co-supervision without losing quality lecturers to CGIAR.

To enhance the capacity for collaboration with networks and universities, CGIAR centers should ensure they are aligned to the priorities of African countries. Additionally, partnerships should be enhanced to ensure more equitable sharing of resources and invest in capacity building of partners. By working with NARS and through networks such as RUFORUM, capacity development activities can be more targeted.

RUFORUM has worked with universities to identify their comparative advantage in terms of discipline competency. Different universities then offer programs or become a regional hub, open to students from other universities across the continent. Staff training is offered to support the program and external capacity is brought in where needed. FTA II centers could support this process by identifying universities and programs they wish to support, and by building capacity in a focused way. CIFOR's collaboration with national universities and the International Development Law Organization in Tanzania, Zambia and Mozambique provides one example of an approach to harness the skills of final year law students (see Box 5).

\section{Working with national universities}

Two ICRAF scientists with close ties to Kenyan national universities provided insights on how FTA can support the capacity development of these institutions. Most national universities have the capacity in terms of expertise but lack the resources for student projects (e.g. laboratories and equipment). Programs such as the German Academic Exchange (DAAD, see Box 6) provide great opportunities to support master's and doctoral placements. It is important that supervisors in the CGIAR centers keep their student numbers to a level they can supervise effectively. The capacity development unit at ICRAF supports student placements and could do more to ensure that students are trained in research methods, proposal development, data organization and analysis, and experimental research design, so that supervisors can focus their support on substantive feedback. 


\section{Box 5. CIFOR collaboration with final-year law students at national universities in Tanzania, Zambia and Mozambique and the International Development Law Organization}

CIFOR, in collaboration with the International Development Law Organization (IDLO), worked with finalyear law students in Tanzania, Zambia and Mozambique to assess the legal frameworks for major resource sectors, in order to analyze whether, and to what extent, they enable sustainable investments. These countries' national development plans, cross-cutting laws on land and the environment, and sector-specific laws governing forestry, agriculture, mining and energy reflect sustainability principles, to varying degrees. Relying significantly on these sectors, the countries have witnessed consistent GDP growth in recent years. However, despite their resource wealth and increased investments, poverty and resource degradation persist. Rural populations remain disproportionately affected, with limited access to basic services and increased vulnerability to the impacts of deforestation and climate change. Key insights into four common issues that can hinder or enable sustainable land use investments were identified by the legal assessments. These consist of investment incentives, security of customary land tenure, enforcement of socioeconomic and environmental safeguards, and public awareness and participation. These issues also present rule-oflaw opportunities to support landscape governance aimed at empowering communities, alleviating poverty and contributing to sustainable development.

Source: Dalupan et al. 2016.

\section{Box 6. Strengthening research capacities through partial fellowship programs - DAAD-ICRAF In-country/In-region PhD Fellowship Program}

The German Academic Exchange (DAAD) funds five African PhD fellows annually to undertake their doctoral studies at East African universities and with FTA CGIAR partners. To qualify, applicants must be working as researchers or staff members in academic or research institutions. The university and ICRAF supervisors co-supervise the students, and DAAD pays tuition fees, partial stipends, and contributes towards meeting research costs. The PhD students need to be placed at a German academic/research institution for a period of six months during the course of study. CGIAR partners contribute towards the fellowship and its operational and field costs. As of 2018, 10 students are engaged in this program.

Source: ICRAF, Nairobi

As noted above, CGIAR scientists are often over-stretched; however, they do need to give greater recognition to the importance of future research leaders (CapDev Element 4). This should include identifying and establishing stronger links with national universities to ensure students can benefit from both theoretical and practical insights. In 2018, CIFOR and ICRAF jointly organized two specialist short courses titled, 'How to write a scientific article' to assist 15 young scientists from CIFOR, ICRAF, Bioversity International and ILRI as they embarked on their postgraduate studies. There is also an opportunity to bring in fourth-year students for short internships or to assist in data collection and analysis (as per Box 5). This provides the students with exposure and will help the centers to identify and support promising students. FTA II can also play a role in supporting curriculum development through ANAFE, RUFORUM and directly with universities. It may also be useful to consider supporting training at the level of secondary education, to enhance an appreciation of forests, trees and agroforestry from a young age. 


\subsubsection{Integrating research in development}

As outlined in FP2,"FTA's research in development (RinD) and co-learning with development partner paradigms requires capacity to frame credible and relevant science from which development partners' knowledge needs are met. This is achieved through engaging development partners at relevant scales right from the beginning in an action research mode" (FTA 2017a).

World Vision, a development partner in Kenya, identified a number of areas for capacity development to improve RinD:

- Cultures vary significantly between organizations, and particularly between research and development organizations. FTA and CGIAR centers need to better understand how to communicate and interact with development partners.

- Development partners may need capacity building to understand how research can contribute to development, how the opportunities for research can feed into the development process, and how to interpret the research findings to inform activities.

- Development partners must be engaged in the full research process, from needs identification to production and interpretation of results. Without the bigger picture, it is challenging for them to contribute fully to RinD.

- Research outputs should be produced quickly (to feed into development activities) and be presented in understandable forms (e.g. using graphics and summarizing results in plain language).

Recommendation: Each flagship should develop a strategy to guide a capacity needs assessment and interaction with any new partners. The strategy should include a process for cross-learning, so that each organization understands the other in terms of approach, expectations and language. Additionally, it should include a process for capacity development of partners.

Delivery of intermediary communications pieces is an important consideration. While research quality should not be compromised, more interim communication products. such as working papers, short briefs, infographics, feedback reports and websites should be valuable both for partners and for donors. Communities of practice offer a co-learning model that has been successful in some projects (see Box 7).

\subsubsection{Capacity for outreach, collaboration and capacity building of partners}

The 'strengths and successes' capacity building approach with partners, as well as capacity gaps within the FPs are outlined below.

\section{Strengths and successes in outreach, collaboration and capacity building of partners}

FP1 has worked successfully with research and non-research partners at the national and subnational levels. It has worked through Rural Resource Centers (RRCs) and nursery teams for germplasm supply, through NGOs for project implementation, and with the private sector for specific projects. Additionally, networks have been supported at different times and stakeholder workshops used to interact with a wide range of actors.

FP2 has a good record of working with a range of partners, from national and subnational governments to NGOs and farmers unions. A number of staff across the FP (including in the regions) have excellent capacity to work with development partners and the communities, for example on local knowledge. The 'options by context' work in Kenya has received positive feedback from development partners, and the community of practice interactions (see Box 3 above) have shown demand for the work from the community. 


\section{Box 7. Co-learning to accelerate development impact ${ }^{*}$}

The 'Restoration of degraded land for food security and poverty reduction in East Africa and the Sahel: Taking successes in land restoration to scale' project, supported by the International Fund for Agricultural Development (IFAD) and the European Union (EU) is using an innovative approach to co-learning. By embedding RinD initiatives into development initiatives, this co-learning approach is accelerating development impact. Farmers' experiences are documented and monitored using research methods, and the results are used to adapt technologies to the context of the farmer. Under the project, over 20,000 farming households are evaluating land restoration options on their farms through structured co-learning among communities of practice in Mali, Niger, Kenya and Ethiopia. Using the co-learning approach, farmers prioritized land restoration options and tested these options in planned comparisons to assess which worked best for different farmers. Lessons from these comparisons are then shared through communities of practice that bring farmers, community facilitators, NGO and government extension staff, private sector actors, and researchers together, to share knowledge and experience about what works on the ground, where and for whom. This represents a key change in the way development initiatives are implemented, giving a larger role to farmers in selecting and adapting options for scaling up and evaluating their performance. At the same time, structured dialogue helps development actors and researchers understand each other's needs and expectations, leading to generation of timely research outputs that are incorporated in the development cycle.

Note:

* See also: http://www.worldagroforestry.org/project/restoration-degraded-land-food-security-and-poverty-reduction-eastafrica-and-sahel-taking

Source: Coe et al. 2014

FP3 has had success in working with a number of partners on zero deforestation initiatives, understanding the complexities and diversity of 'smallholders' and developing sustainable business models for globally-traded commodities, with particular reference to palm oil, timber and beef value chains. The FP has also presented research findings at high-level events, increasing the visibility of results.

FP4 has strong relationships with partners, including governments, NGOs and local community. The work has been described as very place-specific and, using structured approaches, FP4 works with local governments, NGOs, universities and NARS. The National Agroforestry Policy in India was a great success and brought experience from the Alternatives to Slash-and-Burn (ASB) program, with partnerships spanning 20 years, for cross-country learning and communication mechanisms. The partnership with Tropenbos (TBI) and the adaptive learning approach both demonstrate great promise in the FP, according to one respondent.

FP5 has recorded success in working with a large number of committed partners - seven of which are supported through FTA II - to contribute to climate mitigation and adaptation through the implementation of NDCs and to identify how governments and other actors can increase their level of ambition. The FP informed the United Nations Framework Convention on Climate Change Talanoa Dialogue in 2018. ${ }^{4}$ Partnerships have been key in co-developing science (outputs) and how they use the knowledge generated in the FP for their decision-making (outcomes). 


\section{Capacity development of partners}

A respondent from FP1 outlined that the national government capacity varied between countries, with capacity gaps often present where there was weak government commitment. As such, within the sphere of influence, a strong capacity development effort is needed. A perspective from FP2 was that policy makers need to be exposed to complexity through site visits and other mechanisms, so they can understand the need for systems-level work.

It was highlighted in one interview (FP2) that many of the development partners do not have the capacity for delivering research outputs; therefore, capacity building is crucial. It was highlighted however, that assessing technical capacity across development partners is a challenge, and engaging partners and enabling capacity takes considerable time. Use of tools such as outcome mapping (to plan interactions with partners and provide them with regular updates) and data collection through online forms (to allow quick reporting back of interim results) are needed for interaction with development partners.

Partner capacity building approaches and recommendations outlined by the FPs included:

- Short courses on key elements of tree propagation and management. If partners apply for training and a minimum criteria is set, this will ensure interest among trainees and that training fits stakeholder needs (FP1).

- Support to masters and PhD students, usually attached to projects (FP1 respondent), is a good opportunity for capacity building; combined with interns, graduate students are open to systems concepts (FP2). While this CapDev support is already taking place in many FPs, including FP3, some felt the efforts spent on students was not sufficiently recognized in staff performance criteria, and additional assistance is needed to help young scientist with i.a. writing and publishing scientific articles (FP3 respondents).

- CIFOR scientists and world-renowned advanced research centers provide cutting-edge science and training in research methods to young academics from developing countries. In 2018 more than 60 young researchers were undertaking BSc, MSc and PhD training through FP5; such students constitute future developing country leaders.

- The African Plant Breeding Academy, a collaboration between the University of California, Davis, NEPAD, Mars and ICRAF, in which African practicing breeders are being trained, provides a good model (see Box 8) (FP1 respondent).

\section{Box 8. African Plant Breeding Academy of the African Orphan Crops Consortium (AOCC)}

The African Plant Breeding Academy (AfPBA), modeled along similar plant breeding academies such as the Seed Biotechnology Center at UC Davis, is a strategic partnership between UC Davis, Mars Inc., NEPAD, and ICRAF, among others. The goal is to train practicing African plant breeders in the most advanced theory and technologies for plant breeding, to support critical decision making around crop improvement. This includes the latest concepts in plant breeding, quantitative genetics, statistics and experimental design. It also includes accurate and precise trait evaluations, development of appropriate strategies to integrate genomics into breeding programs, and experience in identifying and utilizing genomic data and DNA-based markers in breeding programs. The instructors are internationally recognized experts in plant breeding and seed technology. The program is delivered in three 2-week sessions at World Agroforestry in Nairobi, Kenya. Between 2013 and 2018, 85 breeders were trained during three cycles.

Source: ICRAF Capacity Development Unit, Nairobi 
- Access and use of manuals and online tools is an important mechanism to enhance capacity; however, the uptake and use of tools requires further investigation and resources (FP1 and FP3 respondents).

- Websites and smartphone apps are useful to build capacity (FP1 respondent) and opportunities to develop massive open online courses (MOOCs) should be investigated, e.g. a MOOC on Climate Change building using the 2011 Climate Change Toolbox (FP5 respondent).

- Embedding training elements in each project through students, field schools and engagement of stakeholders, including development of training manuals through a client-driven co-design process, as done by CATIE, is recommended (FP2 and FP4 respondents).

The CGIAR Capacity Development evaluation recommendation, supported by the SMB, was to deemphasize direct training efforts of local end-users as this is not considered a competitive strength of the CGIAR centers. Within FP4 as well as FP1 and FP2, direct interaction with end-users may take place, for example, through harnessing local knowledge and provision of tree germplasm. As FTA works with complex systems, centers often need to equip extension providers with new knowledge and skills. These local-level interactions suggest that, in some situations, the SMB recommendation may need to be reviewed.

\section{Capacity gaps in the FPs for outreach, collaboration and capacity building of partners}

Some gaps outlined during interviews with FP staff included translational and collaboration capacities, which are discussed in more detail below.

Translational capacities involve the ability to take results from research products and share them in the language of the intended audience. More and better communication with partners is needed, according to the study participants. To communicate effectively to our partners, we must produce understandable products that are relevant to different types of partners, including private sector actors and policy makers. Internal capacity needs identified through the interviews included the need for social media training for scientists (e.g. how to share research via Twitter), as well as the need to capture lessons from successful projects and develop effective communication materials (FP1 respondents). This is critical to share lessons and results rapidly with partners, including the community (FP2 respondent). Examples of successful communication products exist across the flagships; for example FP3 successfully developed a series of Infobriefs on palm oil governance and financing of the palm oil sector that have been used to inform national decision-makers.

An interview with the head of communications for ICRAF indicated that capacity development work in communications is needed for ICRAF staff; activities such as training in media writing and use of social media have already taken place or are planned at an institutional level. Opportunities such as collaboration with 'The Conversation', a not-for-profit media outlet that sources content from academics and researchers, links scientists directly to the media and builds their capacity in writing for a wider audience. To enhance FTA communications, the FPs will need to find center-based dedicated staff time and investigate opportunities to raise resources for targeted communications work.

Recommendations to enhance translational capacity include:

- systematic mobilization of communications staff and financial resources within centers to address critical outreach areas, such as development of infographics.

- encouragement of staff to use social media, online platforms such as 'The Conversation' and blogs to share their research outputs.

- clear communications plans developed for FPs, including identifying clear messages for different audiences and frequency of activities, and ensuring partners are engaged throughout project timeframes.

- investigation of opportunities to share communication resources and skills across FTA II partners. 
Collaboration capacity is considered the ability to build strong relationships. Many respondents in the study felt that better collaboration with partners is needed in FTA II. This was particularly felt in terms of building trust with partners by sharing both successes and challenges, and by engaging partners early in the proposal development process. Early engagement enhances demand-driven research and an understanding of the bigger picture among all partners (FP2, FP4 and FP5 respondents). Under FP3, the need to engage more effectively with NARS, conservation and development NGOs and other local partners, as well as to identify new partners to support strategic partners in some countries, was identified. Greater networking with the private sector and greater engagement was identified as a gap under FP5 and FP4. It was reported, however, that a reduction in funding that left fewer resources for partners was a challenge to building partnerships.

Recommendations to improve collaboration capacity arising from the interviews include:

- Enhance demand-driven research. This could be achieved through established platforms such as the Global Donor Platform for Rural Development (hosted by GIZ) annual meetings and/or specialized meetings and Innovation Forum events with corporate actors. Innovation platforms also provide an opportunity for both capacity development and to ensure demand-driven research. The SMB recommended that centers share their experience of innovation platforms to determine how effective they have been in the past.

- Add matrices to the performance evaluation that consider quality of research outputs and collaboration. While the SMB board has maintained the number of ISI publication as one of three indicators for research outputs, additional metrics are needed to reflect broader changes across the CGIAR system.

- Use community facilitators to effectively liaise between NGO staff, research centers and the community.

- Promote transdisciplinary work, such as SHARED (see Box 3) that can integrate science, practice and policy.

- Invest in soft skill development, such as facilitation skills (see Box 9) in staff. This recommendation may apply more at an institutional level but is important across all FTA flagships.

- Establish sustainable local partners and focus projects around them. These would be respected partners that have a long-term presence in a country, such as strategic partners and intergovernmental organizations.

- Develop strong and targeted training materials that can be taken up by partners in an effective and efficient way. Invest in short courses to build the capacity of partners in countries with weak capacity, and train on a complete package (seed/seedling systems, domestication etc.).

\section{Box 9. Building capacity for facilitation and soft skills enhancement - SHARED Decision Hub Facilitator Training}

Following expressed interest from ICRAF staff, in 2017 the SHARED Decision Hub offered facilitator training to 25 participants from the organization across different units and age groups. Training covered topics such as how to get people talking, planning facilitation activities, managing working groups, troubleshooting, summing up and facilitation tools and tips. Following the training, facilitators from the SHARED Hub have supported various individuals and units in the organization to develop their facilitation plans for events. The intention of the training and the follow-up support was to ensure a growing pool of confident and skilled facilitators exist in the organization. Facilitation and soft skill capacities are essential to supporting FTA work. Source: SHARED team, Nairobi 


\subsection{Capacity to mobilize financial resources}

To understand the interviewees' progress with resource mobilization at flagship and CoA levels, they were asked several questions: (i) what are the teams' capacities and experiences in raising funds? (ii) what are the critical gaps and significant risks? and (iii) what is missing for success in resource mobilization?

Resource mobilization emerged through the interview process as a key area where respondents felt there was capacity for improvement, so that research outputs can be achieved. It was generally agreed that the reduction in funds available to FTA II through Window 1 and Window 2 (W1/W2) has made progress towards delivering outputs and delivering on the TOC challenging or at least slower, as most FPs are relying on funding through bilaterals (FP3, FP4 and FP5 respondents). It was recognized that even small amounts of W1/W2 funding could be extremely useful when aligned to larger bilateral grants (FP2 and FP3 respondents). However, respondents also highlighted that it is a challenging time for fundraising and that the overall funding available has reduced, particularly in Asia and Latin America. One respondent outlined that, while FTA does not support their fundraising directly, being in a program with defined direction and priorities has streamlined their work, thus supporting resource mobilization (FP1 respondent).

A number of recommendations to enhance FP resource mobilization that are relevant to FTA II include:

- Enhance FTA branding and communications to raise its profile and showcase the work (FP1 and FP5 respondents). Need to clearly define the focus of each FP so that it can be communicated clearly to donors (FP2 respondent), while still allowing flexibility to respond to their interests and needs (FP3 and FP4 respondents).

- FTA II management should engage at the highest level with large donors (IKI/Global Climate Fund etc.) and negotiate a process for developing large, coherent and strong proposals that are 'fantastic' (FP2 respondent). These could be cross-flagship (FP3, FP4 and FP5 respondents). FTA II needs to invest more funding and time in preparing strong proposals over the course of a year, and should negotiate this directly with the large donors to be engaged in setting the agenda, instead of being reactive and 'last-minute.'

- FTA II needs to have a stronger development progress vision of what it hopes to achieve and should use clear language with donors about systematic change by moving beyond orthodox project cycles.

- Additional donor sensitization is needed to highlight the critical importance of processes to achieve outcomes and impacts during project implementation. This should encompass a dialogue on how to assess longer-term development outcomes and impacts of research projects.

- Across FTA II, the management team needs to coherently convey that the projects lead towards larger outcomes/impact through the ToC, and should look beyond the projects to the process and engage donors for longer-term commitments (FP4 respondent).

- A fundraising strategy (coordinated resource mobilization) is needed that looks at how to compete collectively against consultants and how to show that the higher quality and comprehensive approach (and wider systems thinking) of the work deserves higher investment costs; FPs are a place to bring about this coordination (FP2 respondent). This should also consider the role and performance of strategic boundary partners in resource mobilization.

- FTA flagship leaders need to understand and assess the opportunities for CGIAR centers to provide links to the corporate work in social responsibility and what impact and outcomes could be addressed.

- The Steering Committee should address financial procedures to allow for smaller fund transfers and for money to be allocated based on local/regional project development ideas, rather than being redistributed (FP4 respondent). 


\subsection{Managerial capacities}

The interview process engaged respondents across roles, including cluster and flagship leads, scientists and strategic partners. This breadth of interviewees highlighted a number of areas and levels within the management process and structure that could be improved.

These core areas are highlighted in Table 4, which shows links to recommendations to address areas of concern for capacity gaps, as well as the suggested scale at which the recommendations apply.

Table 4. Core areas and linked recommendations to address capacity gaps*

\begin{tabular}{|c|c|c|}
\hline $\begin{array}{l}\text { Area that needs } \\
\text { addressing }\end{array}$ & Recommendations & $\begin{array}{l}\text { Suggested } \\
\text { responsibility }\end{array}$ \\
\hline $\begin{array}{l}\text { Clarity on decision- } \\
\text { making roles and } \\
\text { power }\end{array}$ & $\begin{array}{l}\text { Internal consultation on decision making, to highlight gaps and areas } \\
\text { to enhance communication. Consultation to be summarized internally } \\
\text { through an infographic to show structure of roles and key decision- } \\
\text { making points and focal points. }\end{array}$ & $\begin{array}{l}\text { Flagship leaders } \\
\text { and FTA Steering } \\
\text { Committee }\end{array}$ \\
\hline $\begin{array}{l}\text { Criteria to distinguish } \\
\text { performance }\end{array}$ & $\begin{array}{l}\text { Human resource units to undertake a formal revision of the existing } \\
\text { criteria used to distinguish performance at different levels and to } \\
\text { ensure a broadening of the criteria as suggested. }\end{array}$ & $\begin{array}{l}\text { Human resource units } \\
\text { within centers }\end{array}$ \\
\hline \multirow{2}{*}{$\begin{array}{l}\text { Clear and accessible } \\
\text { management strategy } \\
\text { and work plan for } \\
\text { each flagship }\end{array}$} & $\begin{array}{l}\text { Team building exercises and facilitated dialogue to reduce } \\
\text { competition and facilitate collaboration. }\end{array}$ & \multirow[t]{2}{*}{$\begin{array}{l}\text { Establish flagship } \\
\text { management units? }\end{array}$} \\
\hline & $\begin{array}{l}\text { Clarity on each center's strength, remit and niche and outlining a } \\
\text { strategy to build cross-center alliances through a fair negotiation }\end{array}$ & \\
\hline \multirow[t]{4}{*}{$\begin{array}{l}\text { Lack of accountability } \\
\text { or transparency in } \\
\text { feedback }\end{array}$} & $\begin{array}{l}\text { Establish system for structured dialogue and hierarchy, with clear flow } \\
\text { and tracking of feedback between research staff to managerial and } \\
\text { tracking feedback and input. }\end{array}$ & \multirow{4}{*}{$\begin{array}{l}\text { External negotiation } \\
\text { agency such as } \\
\text { SHARED hub, staff } \\
\text { associations and } \\
\text { through more official } \\
\text { channels governed } \\
\text { by human resource } \\
\text { unit engaged with FTA } \\
\text { Management Team }\end{array}$} \\
\hline & Examples of software options that could assist managerial capacity: & \\
\hline & $\begin{array}{l}\text { Weekdone - can also be customized with specific questions and } \\
\text { prompts, and provides reporting on alignment between staff } \\
\text { objectives and flagship goals. }\end{array}$ & \\
\hline & $\begin{array}{l}\text { Hppy - allows understanding what factors are affecting moods and } \\
\text { morale and tracks them over time. Flagship managers could customize } \\
\text { questions, with quick reply options from research staff. }\end{array}$ & \\
\hline \multirow[t]{3}{*}{$\begin{array}{l}\text { Managing internal } \\
\text { networking and } \\
\text { collaboration among } \\
\text { FTA staff }\end{array}$} & $\begin{array}{l}\text { Establish an internal networking portal, with a clear FTA organogram } \\
\text { outlining each person's role, areas of expertise, networks, background } \\
\text { and partnership opportunities. }\end{array}$ & \multirow{3}{*}{$\begin{array}{l}\text { Human resource unit / } \\
\text { consultancy with terms } \\
\text { of reference to develop } \\
\text { an accessible portal for } \\
\text { an internal networking } \\
\text { and communication } \\
\text { system. }\end{array}$} \\
\hline & $\begin{array}{l}\text { Include a curated introduction to the portal and internal training } \\
\text { session on use and accessibility. }\end{array}$ & \\
\hline & One example could be Pingboard, which has good mobile accessibility. & \\
\hline \multirow{2}{*}{$\begin{array}{l}\text { Addressing concerns } \\
\text { surrounding } \\
\text { motivation and the } \\
\text { metrics used for } \\
\text { success }\end{array}$} & $\begin{array}{l}\text { Evaluate and weight metrics being used as outcome successes, } \\
\text { including a critical review of the current emphasis on quantity of } \\
\text { publications. }\end{array}$ & \multirow[t]{2}{*}{$\begin{array}{l}\text { Representatives from } \\
\text { each center's human } \\
\text { resource unit. }\end{array}$} \\
\hline & $\begin{array}{l}\text { Initiate human resource consultations with staff and a suggested matrix } \\
\text { of evaluation to integrate criteria around collaborations, partnership } \\
\text { establishment and research outreach to include communications, social } \\
\text { media and publication quality and quantity. Core research staff should } \\
\text { provide input on publication impact outputs. }\end{array}$ & \\
\hline
\end{tabular}

Note

* These will also need to be revised and updated as a function of the outcomes of the Joint Task Force process. See, for example, CIFOR-ICRAF Institutional Linkages Update - June 2018 and the results of the CIFOR-ICRAF Institutional Viability and Prospectus survey, 8 June 2018. 


\section{Capacity of FPs to deliver on research outputs}

Flagships are intended to interact with each other by exchanging results, knowledge, information and material in order to assist with the delivery of research. Consequently, the interviews aimed to probe the respondents accordingly on perceptions of key gaps and opportunities to deliver research outputs. The matrix presented in Table 5 provides suggestions on capacity enhancement to meet progress markers for three example flagships in terms of expected outcomes, and integrates interview feedback and capacity enhancement recommendations.

Table 5. Matrix of capacity enhancement recommendations for select progress markers in three selected flagships

\begin{tabular}{l}
\hline Progress marker \\
Conservation NGOS are actively involved in the co- \\
development, uptake and integration of new methods and \\
tools to inform their TGR policy influence \\
\hline Targeted public and private sector actors are positively \\
engaging with data and evidence on TGR \\
Targeted stakeholders are actively participating in well- \\
designed and structured capacity development initiatives
\end{tabular}

Targeted actors are actively involved with co-developing and implementing new methods, knowledge and tools to accelerate tree domestication and genetic gain

\section{Suggested recommendation}

Use methods such as human-centered design to actively engage target end-users in the co-design of research and communication outputs

Clear communication and active relationship building to ensure capacity building is demand-driven and catered to at the appropriate level

Private and public suppliers are actively involved with coUse targeted stakeholder engagement methodologies and approaches such as SHARED to allow for internal communication within key public and private sector partners developing and using innovative delivery and extension models and options

Conservation NGOs are actively campaigning for evidencebased TGR safeguarding policies and practices

Targeted public and private sector actors have communicated their intent to, and plans for, taking action on policy recommendations

Targeted public and private sector actors have put concrete plans in place to act on TGR safeguarding using FP1 decisionsupport tools

Targeted public and private sector actors have domesticated new, context-appropriate trees with high impact potential

Relationship building with key private sector actors

Targeted public and private sector actors prioritize new and improved tree traits based on demand, inclusivity and appropriateness

NARES and NGOs adopt FTA methods and tools

Communication and private sector engagement process to package research.

Learning example sharing between regions and FTA protocol for private sector engagement with key steps and success strategies.

Dedicated relationship management with focal staff within NARS

National and subnational policy makers use FTA briefs in the design of policy

Research outputs are clearly structured within national and subnational policy frameworks to allow for clear entry points on how research supports aspects of the development plan

Public and private actors adopt FTA-informed certification Use of existing successful modes and case studies approaches and performance standards of success, such as policy reform within India, as a benchmark for success factors

Private sector market actors engage in value chain innovation and embrace new relationships with producers

State, provincial and local governments implement $A F$ and forest policy reforms 
Table 5. Continued

\begin{tabular}{|c|c|}
\hline Progress marker & Suggested recommendation \\
\hline $\begin{array}{l}\text { Universities, colleges and schools adopt curricula and use } \\
\text { teaching materials }\end{array}$ & \multirow{3}{*}{$\begin{array}{l}\text { Relationship building with local level organizations to } \\
\text { co-develop tailored and practical communication of } \\
\text { research, as suggested by users at appropriate levels }\end{array}$} \\
\hline $\begin{array}{l}\text { Public and private investors provide patient capital to finance } \\
\text { smallholder initiatives }\end{array}$ & \\
\hline $\begin{array}{l}\text { Smallholder farmers are reached by, adopt and adapt } \\
\text { agroforestry, forestry and market opportunities }\end{array}$ & \\
\hline $\begin{array}{l}\text { Centers of landscape education and sustainability science } \\
\text { are engaged }\end{array}$ & \multirow[t]{4}{*}{$\begin{array}{l}\text { Internal mechanism to track and share learning } \\
\text { reflections by research staff }\end{array}$} \\
\hline $\begin{array}{l}\text { FTA-inspired scientists are engaging with existing } \\
\text { and emerging efforts to improve or restore landscape } \\
\text { multifunctionality at local government level in at least } 10 \\
\text { countries }\end{array}$ & \\
\hline $\begin{array}{l}\text { Landscape teams are assessing the current strength of } \\
\text { the learning cycle as a basis for targeted learning and } \\
\text { improvement }\end{array}$ & \\
\hline Landscape teams are engaging in the learning cycle & \\
\hline $\begin{array}{l}\text { Practitioners are flagging emergent issues with current } \\
\text { theories of change }\end{array}$ & Need for a rapid and transparent sharing mechanism \\
\hline $\begin{array}{l}\text { Universities and training centers are using new tools and } \\
\text { case studies as part of curricula }\end{array}$ & Communication and social media outreach \\
\hline
\end{tabular}




\section{Monitoring and reporting}

The new system for Managing Agricultural Research for Learning and Outcomes (MARLO) is intended to monitor and report on all types of capacity development activities. MARLO is an online system for results-based program planning, reporting and learning, to be used by the CRPs, including FTA.

The SMB commentary outlined that capacity development reporting can take place through MARLO as one of the nine common indicators. Stories of capacity development activities can also be featured in the annual performance report.

A new one-page simple online reporting form will be developed to ensure that all training courses and CapDev activities are recorded by all scientists. In addition, to ensure that capacity development'success stories' are shared, a series of tracer, outcome and case studies will be commissioned by the proposed Learning Unit to identify additional lessons learned on effective capacity development approaches.

Another avenue to capture capacity development should be at the staff level, through performance evaluations. Inclusion of metrics that consider quality of research outputs and collaboration in terms of communicating with FTA institutions and partners would be valuable. 


\section{Recommendations across FTA II to enhance capacity to deliver on research outcomes and achieve greater impacts}

The analysis and recommendations contained within this document result from data collated from more than 70 interviews conducted with flagship and cluster leaders, as well as key actors within the FTA II management team and partner organizations. The key recommendations that cut across FTA II are:

\section{Develop and communicate a clear vision for FTA II}

Enhanced understanding of the vision for FTA is needed to support resource mobilization efforts. Once developed, greater communication of the vision is needed. Resource mobilization should then take place across FTA institutions to strengthen proposals.

\section{Review and strengthen the strategic partner composition of FTA II}

As highlighted in the FTA II Full Proposal partnership strategy, while the strategic partnership arrangement was comprehensive at the time of development, regular review is essential to improve influence on the creation of an enabling environment. A review based on geographical and institutional focus as well as capacity to deliver would provide valuable insight to understand if the current composition of FTA II strategic partners is sufficient to deliver on the FPs TOC.

\section{Flagships should develop a clear strategy for capacity development}

Each FP should have a capacity development strategy or activities clearly articulated and linked to their TOC, including CGIAR CapDev elements. These activities should target both FTA II staff and partner institutions. FTA II staff capacity development is needed in terms of collaboration and research translation, and a number of opportunities exist for cross-institution learning. Development partners capacity strengthening could include training on how to interpret and use research outputs and engagement through the research cycle to enhance understanding and improve demand-driven research.

\section{Establish a small dedicated FTA II Capacity Development team - a 'Learning Unit' - to implement the new CapDev Strategy and linked Communities of Practice}

As CapDev at scale depends on its integration in the portfolio of bilaterals, additional thought on requirements/incentives for bilateral projects design (including donor sensitization) and possible changes to CGIAR scientist performance metrics to provide incentives to promote greater attention (to detail) on 
CapDev activities are needed. Additionally, the establishment of regional communities of practice could enhance capacity development efforts across FTA II.

\section{Greater investment in capacity development of national research institutions is needed}

To achieve this:

- FTA institutions must align to national priorities.

- Opportunities to support exchanges, placements and sabbaticals between FTA II centers, NARS and universities should be strengthened.

- Continued investment in masters and doctoral student placements is needed, with greater center focus on capacity development of those students.

- Strategic engagement is needed with universities through regional networks for curricular or program development.

- Strong and targeted training materials that can be taken up by partners must be co-developed.

- Modalities should be developed to take full advantage of the experience and facilities of CIFOR and ICRAF HQs in Bogor and Nairobi, respectively. This can be done through, for example, potential replication of a short-term 'Landscape Governance' course originally developed in Southeast Asia (in collaboration with Wageningen University/Centre for Development Innovation), to East and Southern African and Latin American contexts.

\section{Emphasize research and development capacities at subnational levels of governance through a broader array of partners.}

- Create an external outlook to have more innovation in partnerships, think tanks, universities, local governments and the private sector. Explore opportunities through IDRC's Think Tank Initiative.

- Build social capital by reviewing examples of well-functioning working relationships among colleagues and the key steps that lead to these.

\section{Invest in partnership models that have been successful}

A number of approaches (additional to those outlined above) have been used effectively for capacity development. These include innovation platforms (although more investigation is needed as per the SMB recommendation) and multi-stakeholder platforms. Some other examples include:

- Regular FTA 'innovation and science' webinars. These could be facilitated on a rolling basis by different scientists. Trained facilitators and engagement specialists could provide a template for structuring the webinars, to be run informally but with specific outputs and underlying incentives to increase research connections and innovation sharing. A good example is the 'Cool Water' symposium held in 2017.

- Harness the opportunities provided by the CIFOR-led Global Landscapes Forum events. Similarly, in-country models such as the UNIKIS-CIFOR Science Week held with the University of Kisangani, DRC for the past 5 years should also be explored.

- Take advantage of the critical mass of events where there are a number of people in one place that have similar interests to enhance collaboration.

- Explore the possibilities of FTA/CIFOR/ICRAF being able to identify and sub-contract alternative providers of CapDev, such as the recent GLF/CIFOR contract established with CDI/WUR to promote the Landscape Academy. 


\section{Bibliography}

[CIFOR-ICRAF] Center for International Forestry Research, World Agroforestry. 2018. CIFOR-ICRAF Institutional Linkages Update - June 2018. Unpub. Manus. 3 pp.

Bioversity International. 2014. 10 year Strategy. Agricultural biodiversity nourishes people and sustains the planet. Bioversity International, Rome.

Bioversity International. 2015. Gender Research Fellowship Programme: Results and ways forward. Impact Assessment Brief \#17. Bioversity International, Rome.

Callo-Concha, D., Denich, M., Ul Hassan, M.M., Place, F., and Wardell, D.A. 2017. Lessons for research, capacity development and policy in agroforestry for development. Agroforestry Systems 91:795. DOl: 10.1007/s10457-017-0085-6

CGIAR. 2015. Capacity Development Framework. Prepared by CGIAR Capacity Development Community of Practice for the second round of CGIAR Research Programs. CGIAR Consortium Office, Montpellier, France. https://cgspace.cgiar.org/bitstream/handle/10947/3414/CGIAR\%20Capacity\%20 Development\%20Framework\%20Working\%20Draft.pdf

CGIAR-IEA. 2017a. Evaluation of Capacity Development Activities of CGIAR: Vol I - Report. Independent Evaluation Arrangement (IEA) of CGIAR, Rome. https://cas.cgiar.org/sites/default/files/pdf/CapDev_ Eval-Report-Vol-I-_-Report.pdf

CGIAR-IEA. 2017b. Evaluation of Capacity Development Activities of CGIAR: Vol II - Annexes. Independent Evaluation Arrangement (IEA) of CGIAR, Rome. https://cas.cgiar.org/sites/default/files/pdf/CD-EvalReport-Vol-II-Annexes.pdf

CGIAR-IEA. 2017c. Evaluation of Capacity Development Activities of CGIAR: Vol III - Issue Papers. Independent Evaluation Arrangement (IEA) of CGIAR, Rome. https://cas.cgiar.org/sites/default/files/ pdf/CD-Eval-Report-Vol-III-Issue-Papers.pdf

CGIAR-IEA. 2017d. Evaluation of Partnerships in CGIAR. Independent Evaluation Arrangement (IEA) of CGIAR, Rome, Italy. http://iea.cgiar.org

[CIFOR] Center for International Forestry Research. 1996. Annual Report 1995. CIFOR, Bogor, Indonesia. www.cifor.org/library/131/

CIFOR. 2010. Annual Report 2009: The turning point. CIFOR, Bogor, Indonesia. www.cifor.org/ library/3095/ CIFOR. 2017a. Annual Report 2016: Putting forests and people on the global agenda. CIFOR, Bogor, Indonesia. www.cifor.org/library/6477

CIFOR. 2015. Improving governance by building capacity in the Democratic Republic of Congo; CIFOR panel, World Forestry Congress, Durban 7-11 September 2015

https://www.foreststreesagroforestry.org/publications/research-publication/?title=improvinggovernance-by-building-capacity-in-the-democratic-republic-of-congo\&id=314563145631456

CIFOR. 2017a. CIFOR Strategy 2016-2025. Stepping up to the new climate and development agenda. CIFOR, Bogor, Indonesia. www.cifor.org/library/5959/

CIFOR. 2017b. CIFOR Priorities 2017: Advancing Research for Forests and People. pp. 41-43. CIFOR, Bogor, Indonesia. https://www.cifor.org/library/6403/

CIFOR. 2017c. FTA II collated comments to the IEA evaluation of Capacity Development Activities of CGIAR. Unpub. Manus. 4pp. https://www.foreststreesagroforestry.org/publications/ research-publication/?title=fta-ii-collated-comments-to-the-iea-evaluation-of-cgiar-capdevactivities\&id=314543145431454

Clendenning, J., Elias, M. and Basnett, B.S. 2019. At the intersection of gender and generation: Engaging with 'youth' in the CGIAR Research Program on Forest, Trees and Agroforestry. FTA Brief No. 3. FTA, Bogor, Indonesia. www.cifor.org/library/7346/

Coe, R., Sinclair, F., Barrios, E., 2014. Scaling up agroforestry requires research "in" rather than "for" development. Curr. Opin. Environ. Sustain. 6, 73-77. https://doi.org/10.1016/j.cosust.2013.10.013 
Dalupan MCG, Haywood C, Wardell DA, Cordonnier-Segger M-C and Kibugi R. 2015. Building enabling legal frameworks for sustainable land-use investments in Zambia, Tanzania and Mozambique: A synthesis. Occasional Paper 140. Bogor, Indonesia: CIFOR. www.cifor.org/library/5753/

Ellison D, Morris CE, Locatelli B, Sheil D, Cohen J, Murdiyarso D, Gutierrez V, van Noordwijk M, Creed IF, Pokorny J, et al. 2017. Trees, forests and water Cool insights for a hot world. Global Environmental Change 43 (2017): 51-61

FTA. 2017a. CGIAR Research Program on Forests, Trees and Agroforestry. Revised Phase II Full Proposal 2017-2022. FTA, Bogor, Indonesia. http://www.foreststreesagroforestry.org/wp-content/uploads/ pdf/2FTA-CRPandFPNarrativesProposal2017-2022.pdf

FTA. 2017b. CGIAR Research Program on Forests, Trees and Agroforestry. Revised FTA Phase II Full Proposal: Annexes. FTA, Bogor, Indonesia. https://www.foreststreesagroforestry.org/wp-content/ uploads/pdf/4FTA-Annexes.pdf

[ICRAF] World Agroforestry. 2013a. Capacity Development Strategy 2013-2018. Enhancing the knowledge, use and impact of agroforestry. ICRAF, Nairobi, Kenya.

ICRAF. 2013b. ICRAF Strategy 2013-2022. Transforming Lives and Landscapes with Trees. ICRAF, Nairobi, Kenya.IFPRI] International Food Policy Research Institute. 2014. An Assessment of IFPRI's capacitystrengthening work, 1985-2010. Independent Impact Assessment Report No. 38 and Brief by Arie Kuyvenhoven. IFPRI, Washington DC. https://www.ifpri.org/publication/impact-assessmentifpri\%E2\%80\%99s-capacity-strengthening-work-1985\%E2\%80\%932010-0

Babu, S.C. 2017. Guidelines for conducting capacity needs assessments in IFPRI's policy research and outreach programs. Capacity Strengthening Note 1. IFPRI, Washington DC. http://ebrary.ifpri.org/ cdm/ref/collection/p15738coll2/id/131161

Kuyvenhoven, A. 2018. Capacity development for food policy analysis: What works best? Adding evidence from IFPRI's experience. Development Policy Review 36: 0113-0137. DOI: 10.1111/dpr.12221

Leeuwis, C., Klerkx, L. and Schut, M. 2017. Reforming the research policy and impact culture in the CGIAR: Integrating science and systemic capacity development. Global Food Security 16: 17-21. DOI: 10.1016/j.gfs.2017.06.002

[OECD-DAC] Organisation for Economic Co-operation and Development's Development Assistance Committee. 2000. Donor Support for Institutional Capacity Development in Environment: Lessons Learned. Evaluation and Aid Effectiveness 3. OECD-DAC, Paris. 225pp.

CGIAR System Organization. 2017. System Management Board commentary on the evaluation of capacity development activities of CGIAR. CGIAR System Organization, Montpellier, France. 6pp. http://iea.cgiar.org/wp-content/uploads/2016/10/SMB-Commentary_2017_Evaluation_CapDevSubmission-to-SC.pdf

Taylor, P. and Ortiz, A. 2008. Doing things better? How capacity development results help bring about change. IDRC Strategic Evaluation of Capacity Development. Institute of Development Studies (IDS). www.betterevaluation.org/sites/default/files/Taylor_IDRC\%20Strategic.pdf

[UNDP] United Nations Development Programme. 2008. Capacity needs assessment methodology: Users guide. UNDP, New York, NY. www.undp.org/content/dam/aplaws/publication/en/publications/ capacity-development/undp-capacity-assessment-methodology/UNDP\%20Capacity\%20 Assessment\%20Users\%20Guide.pdf

Vallejo, B. and When, U. 2016. Capacity development evaluation: The challenge of the results agenda and measuring return on investment in the Global South. World Development 79: 1-13. DOI: 10.1016/j. worlddev.2015.10.044

Watkins, C., Zavaleta, J., Wilson, S. and Francisco, S. 2017. Developing an interdisciplinary and crosssectoral Community of Practice in the domain of forests and livelihoods. Conservation Biology 32(1): 60-71. DOl: 10.1111/cobi.12982

Watson, D. 2010. Measuring capacity development. Combining the "best of two worlds" in monitoring and evaluation of capacity development. In: Ubels, J., Acquaye-Baddoo, N-A., and Fowler, A. (eds). Capacity Development in Practice. London: Earthscan. pp. 251-263. 


\section{Appendices}

\section{Appendix 1. List of FTA operational priorities}

(the order does not imply any prioritization within the list)

1. Restoration of forests and landscapes, to carry out research on different aspects (from genetic resources to management modes, costs and benefits, and policy and governance options) and to integrate findings and emerging lessons into the main policy platforms and governance processes.

2. Plantations and tree crop commodities, including timber and high-value tree crop plantations, namely tea, coffee, cocoa, oil palm and rubber, and addressing the economic, social and environmental challenges and opportunities of land-use intensification through plantations.

3. Enhanced nutrition and food security, to investigate how tree-based agroecosystems and changing patterns of land use and productive activities at the landscape scale interact with market forces to cause changes in local diets in many countries, and what can be done about it.

4. Biodiversity, safeguarding and conservation in forests and agroforestry systems, for productivity and resilience of these systems.

5. NDC $\mathbf{s}^{5}$, supporting countries in meeting their NDC objectives through an improved use of their forests and tree-based resources.

6. Bioenergy and biomaterials as an essential part of low-emission development strategies and policies. How can they be developed, especially in degraded lands, and how to broaden the species basis?

7. Blue carbon and peatlands, providing knowledge on eco-hydrology and ecosystem services, on carbon stocks dynamics, and on productivity to devise specific restoration options.

8. Climate change adaptation: FT\&A resources are key to the adaptation of forest-dependent communities and agricultural systems to climate change, and must themselves adapt.

9. Landscape governance as it relates to agriculture, forestry and other land uses, and to the livelihoods they sustain.

10. Gender equitable outcomes, aiming at integrating a gender equality and social inclusion perspective - including attention to issues of generation (youth) across the FTA portfolio.

11. Silvopastoral systems, for production, fodder, shade, soil fertility and biodiversity. Retaining trees on pastures can halt and reverse degradation following deforestation.

12. Market-based agroforestry-forestry, to deliver evidence of the return on investment, and provide practical strategies for overcoming the time-lag between investment and returns.

13. Farm-forest policy interface, to better understand policy constraints, and embed FTA methods, approaches, tools and technologies into major national agroforestry scaling-up programs.

14. Agroecology, emphasizing integrated agro-ecological approaches that include trees in agroecosystems for improving smallholder livelihoods.

15. Livelihood trajectory modeling and assessment, to capture the likely impact of adopting FTA innovations on smallholder livelihoods in a range of different contexts.

16. Inclusive finance and business models, and related institutional factors to help address barriers faced by smallholders and improve value-chain coordination and learning.

5 Nationally Determined Contributions of the Paris Agreement on Climate Change 
17. Innovating finance for sustainable landscapes, to understand the potential of responsible finance for providing incentives for the uptake and upscaling of sustainable production practices.

18. Public and private commitments to zero deforestation, as still little is known about the actual social, economic and ecological impacts of those commitments.

19. Orphan tree crops, to support their genetic characterization and their domestication to improve nutrition, as well as for resilience and adaptation to climate change and environmental stresses.

20. Effectiveness of approaches to sustainable supply, to understand the role of supply chain arrangements to halt deforestation, and how territorial approaches can facilitate that process.

21. Quality of FTA research for development (R4D), to devise better research, learn from experiments, and improve the overall performance of FTA as a research-for-development program.

22. Sentinel landscapes: FTA had devised its own setup to observe changes in landscapes, their causes and consequences. Where does this setup stand? How to move forward?

23. Foresight, to identify emerging trends in land use and forests, trees and agroforestry, possible futures and drivers of change, and their potential to contribute to sustainable development.

24. Tree-crop commodities, to address the challenges and leverage the potential of cocoa, coffee and other smallholder tree-crop commodities for sustainable development.

25. Tree seeds and seedlings delivery systems, to address the considerable needs for appropriate tree planting material at scale in order to face the challenges of renewal and improvement of current trees, the need to adapt to climate change, to contribute to its mitigation, and to restore forests and land. 


\section{Appendix 2. Interviewees}

\begin{tabular}{|c|c|c|}
\hline & Flagship / focus of interview & Interviewee name \\
\hline 1 & FP2 & Fergus Sinclair (ICRAF) \\
\hline 2 & FP2 & Tim Pagella (Bangor University) \\
\hline 3 & FP2 & Patricia Masikati (ICRAF) \\
\hline 4 & FP2 & Peter Cronkleton (CIFOR) \\
\hline 5 & FP2 & Emily Smith (ICRAF) \\
\hline 6 & FP2 & Francisco Alpazar (CATIE) \\
\hline 7 & FP2 & Jayaraman Durai (INBAR) \\
\hline 8 & FP2 & World Vision DRYDEV team \\
\hline 9 & FP2 & Leigh Winoweiki (ICRAF) \\
\hline 10 & FP4 & Peter Minang (ICRAF) \\
\hline 11 & FP4 & Meine Van Noordwijk (ICRAF) \\
\hline 12 & FP4 & Terry Sunderland and Amy Ickowitz (CIFOR) \\
\hline 13 & FP4 & Sonya Dewi (ICRAF) \\
\hline 14 & FP4 & Beria Leimona (ICRAF) \\
\hline 15 & FP4 & René Boot (Tropenbos) \\
\hline 16 & FP4 & Valentina Robiglio (ICRAF) \\
\hline 17 & FP4 & Norvin Sepulveda\& Eduardo Somarriba (CATIE) \\
\hline 18 & FP4 & Lalisa Duguma (ICRAF) \\
\hline 19 & FP1 & Ramni Jamnadass (ICRAF) \\
\hline 20 & FP1 & Lars Graudal (ICRAF/University of Copenhagen) \\
\hline 21 & FP1 & Chris Kettle (Bioversity) \\
\hline 22 & FP1 & Ann Degrande and Alain Tsobeng (ICRAF) \\
\hline 23 & FP1 & Sammy Carsan (ICRAF) \\
\hline 24 & FP1 & Jim Roshetko (ICRAF) \\
\hline 25 & NARS & Anthony Esilaba (KALRO) \\
\hline 26 & Communications & Jeanne Finestone (ICRAF) \\
\hline 27 & University & Catherine Muthuri (ICRAF) \\
\hline 28 & University & Alice Muchugi (ICRAF) \\
\hline 29 & Private sector & Christophe Kouame (ICRAF) \\
\hline 30 & NARS & Jackson Mulatya (KEFRI) \\
\hline 31 & University & Moses Osiru (RUFORUM) \\
\hline 32 & FP3 and FP5 & Robert Nasi, DG (CIFOR) \\
\hline 33 & FP3 and FP5 & Vincent Gitz, FTA II Director \\
\hline 34 & FP3 and FP5 & Plinio Sist, UR Forests and Society, Director (CIRAD) \\
\hline 35 & FP3 & Pablo Pacheco, Team Leader (CIFOR) \\
\hline 36 & FP3, CoA1 & Marie-Gabrielle Piketty, CoA1 lead (CIRAD) \\
\hline 37 & $\mathrm{FP} 3, \mathrm{COA} 2$ & George Schoneveld (CIFOR) \\
\hline 38 & FP3, CoA2 & Selma van der Haar (CIFOR) \\
\hline
\end{tabular}




\begin{tabular}{|c|c|c|}
\hline & Flagship / focus of interview & Interviewee name \\
\hline 39 & FP3, COA3 & Herman Servanje, former CoA3 lead (TBI) \\
\hline 40 & FP3, CoA3 & Bas Loumans, new CoA3 lead (TBI) \\
\hline 41 & FP3 & René Boot (TBI) \\
\hline 42 & FP3 & Nian Sadiq (TBI) \\
\hline 43 & FP3 and FP5 & Henk Hoasfloot (TBI) \\
\hline 44 & FP3 & Jean-Marc Roda (CIRAD) \\
\hline 45 & FP3 & Paolo Cerruti (CIFOR) \\
\hline 46 & FP5 & Christopher Martius, Team Leader (CIFOR) \\
\hline 47 & FP5 & Steve Leonard (CIFOR) \\
\hline 48 & SMO & Alain Vidal \\
\hline 49 & SMO & Nadia Manning-Thomas \\
\hline 50 & ILRI & Iddo Dror, former Chair, CGIAR CoP CapDev \\
\hline 51 & IFPRI & Suresh Babu, Head, Capacity Strengthening \\
\hline 52 & IFPRI & Frank Place \\
\hline 53 & University (UNIKIS) & Christian Amani (CIFOR) \\
\hline 54 & Gender and Youth & Marlene Elias (Bioversity International) \\
\hline 55 & Forest Genetic Resources & Riina Jalonen (Bioversity International) \\
\hline 56 & CapDev & Brian Cohen and Yanxia Li (INBAR) \\
\hline 57 & CapDev & Narvin Spulveda (CATIE) \\
\hline 58 & CapDev & Allison Poulos (Bioversity International) \\
\hline 59 & Distance learning & Ulrike Wild and James Mulkerrins (WUR) \\
\hline 60 & CapDev & Cora van Oosten (CDI-WUR/CIFOR) \\
\hline 61 & University & Verina Ingram (WUR) \\
\hline 62 & University & Martin Herold (WUR) \\
\hline 63 & Network & Wilson Kasolo (ANAFE) \\
\hline 64 & Young scientist & Lisa Fuchs (ICRAF) \\
\hline 65 & Young scientist & Esther Kihoro (ILRI) \\
\hline 66 & Young scientist & Vera Vernooij (ILRI) \\
\hline 67 & Young scientist & Laura V. Mukhwana (CIFOR) \\
\hline 68 & Young scientist & Abdub Galgallo (ICRAF) \\
\hline 69 & Young scientist & Jane Wanjara (ICRAF) \\
\hline 70 & Young scientist & Negusse Yigsaw (ICRAF) \\
\hline 71 & Young scientist & Francis Odhiambo (Bioversity) \\
\hline 72 & Young scientist & Julia Boedecker (Bioversity) \\
\hline
\end{tabular}




\section{Appendix 3. Interview guiding questions}

\section{Key questions for Flagship leaders:}

- What is your perception of how your flagship program will contribute to attainment of the CGIAR results framework and the SDGs? (TOC in their language) Enquire on the pathway for this to happen and the key partners and networks that are involved and must be involved, but are not currently.

- Do you think you are on track for your TOC? What are your weak links?

- What are your team's strengths and weaknesses in terms of capacity to deliver on research outputs and to achieve impacts?

- Following the response, enquire on different types of capacities.

- Who are the key people in CoAs, partners and networks that you work with to make this all happen? (build on the interview list - first part of the snowball sample)

- What are the opportunities to mobilize and acquire additional capacities? (Ask about how they are currently doing this, as well as their aspirations or the opportunities they see for the future.)

\section{Questions for CoA leaders and other key strategic partner interviews:}

- What is your perception of how your clusters research outputs will lead to development outcomes?

- What are your team's strengths and weaknesses in terms of capacity to deliver on research outputs and to achieve impacts?

- (Following the response, enquire on different types of capacities.)

- What are the opportunities to mobilize and acquire additional capacities?

\section{Questions for boundary partners or network members:}

- Do you interact with research outputs coming from .... (cluster/FP/name of researcher)? How does this interaction take place? Is it sufficient?

- Were you part of conceptualizing the FP's TOC?

- Do the individuals you work with have the capacity to bring their research to your organization or network effectively? What could be improved?

- What kind of research and research outputs are particularly relevant to your organization's mandate?

- How do you use the research emanating from FTA?

- What are your organization's/network's strengths and weaknesses in interacting with the research outputs for greater development outcomes? (enquire on different capacities)

- What opportunities exist to further the capacity for interaction and use of research outputs (as well as feedback and inputs into the research process)?

\section{Questions for National Agricultural Research Systems (NARS)}

- How does your organization interact with FTA centers, and what is your experience of this interaction and expectations moving forward?

- What type of partnership models have worked or could work well in the future?

- What capacity needs does your organization have in relation to FTA?

\section{Key question for universities:}

- How can FTA build capacity and connections with universities? 

